\title{
The venom-gland transcriptome of the eastern diamondback rattlesnake (Crotalus adamanteus)
}

\author{
Darin R Rokyta ${ }^{*}$, Alan R Lemmon ${ }^{2}$, Mark J Margres ${ }^{1}$ and Karalyn Aronow ${ }^{1}$
}

\begin{abstract}
Background: Snake venoms have significant impacts on human populations through the morbidity and mortality associated with snakebites and as sources of drugs, drug leads, and physiological research tools. Genes expressed by venom-gland tissue, including those encoding toxic proteins, have therefore been sequenced but only with relatively sparse coverage resulting from the low-throughput sequencing approaches available. High-throughput approaches based on 454 pyrosequencing have recently been applied to the study of snake venoms to give the most complete characterizations to date of the genes expressed in active venom glands, but such approaches are costly and still provide a far-from-complete characterization of the genes expressed during venom production.

Results: We describe the de novo assembly and analysis of the venom-gland transcriptome of an eastern diamondback rattlesnake (Crotalus adamanteus) based on 95,643,958 pairs of quality-filtered, 100-base-pair Illumina reads. We identified 123 unique, full-length toxin-coding sequences, which cluster into 78 groups with less than $1 \%$ nucleotide divergence, and 2,879 unique, full-length nontoxin coding sequences. The toxin sequences accounted for $35.4 \%$ of the total reads, and the nontoxin sequences for an additional $27.5 \%$. The most highly expressed toxin was a small myotoxin related to crotamine, which accounted for $5.9 \%$ of the total reads. Snake-venom metalloproteinases accounted for the highest percentage of reads mapping to a toxin class (24.4\%), followed by C-type lectins (22.2\%) and serine proteinases (20.0\%). The most diverse toxin classes were the C-type lectins (21 clusters), the snake-venom metalloproteinases (16 clusters), and the serine proteinases (14 clusters). The high-abundance nontoxin transcripts were predominantly those involved in protein folding and translation, consistent with the protein-secretory function of the tissue.

Conclusions: We have provided the most complete characterization of the genes expressed in an active snake venom gland to date, producing insights into snakebite pathology and guidance for snakebite treatment for the largest rattlesnake species and arguably the most dangerous snake native to the United States of America, $C$. adamanteus. We have more than doubled the number of sequenced toxins for this species and created extensive genomic resources for snakes based entirely on de novo assembly of Illumina sequence data.
\end{abstract}

\section{Background}

Human envenomation by snakes is a worldwide issue that claims more than 100,000 lives per year and exacts untold costs in the form of pain, disfigurement, and loss of limbs or limb function [1-3]. Despite the significance of snakebites, their treatments have remained largely unchanged for decades. The only treatments currently

\footnotetext{
*Correspondence: drokyta@bio.fsu.edu

1 Department of Biological Science, Florida State University, Tallahassee, FL 32306-4295, USA

Full list of author information is available at the end of the article
}

available are traditional antivenoms derived from antisera of animals, usually horses [4], innoculated with whole venoms [5,6]; such an approach is the only readily available option for largely uncharacterized, complex mixtures of proteins such as snake venoms. Although often lifesaving and generally effective against systemic effects, these antivenoms have little or no effect on local hemorrhage or necrosis [7-9], which are major aspects of the pathology of viperid bites and can result in lifelong disability $[4,5]$. These traditional treatments also sometimes lead to adverse reactions in patients [6]. Advances in treatment approaches will depend on a complete knowledge of the 
nature of the offending toxins, but current estimates of the numbers of unique toxins present in snake venoms are in excess of 100 [10], a number not approached in even the most extensive venom-characterization efforts to date [11].

The significance of snake venoms extends well beyond the selective pressures they may directly impose upon human populations. Snake venoms have evolutionary consequences for those species that snakes prey upon $[12,13]$, as well as species that prey upon the snakes [14], and their study can therefore provide insights into predator-prey coevolution. Snake venom components have been leveraged as drugs and drug leads [15-17] and have been used directly as tools for studying physiological processes such as pain reception [18]. In addition to the significance of the toxins, the nature of the extreme specialization of snake venom glands for the rapid but temporary production and export of large quantities of protein could provide insights into basic mechanisms of proteostasis, the breakdown of which is thought to contribute to neurodegenerative diseases such as Parkinson's and Alzheimer's [19].

The eastern diamondback rattlesnake (Crotalus adamanteus) is a pit viper native to the southeastern United States and is the largest member of the genus Crotalus, reaching lengths of up to $2.44 \mathrm{~m}$ [20]. The diet of $C$. adamanteus consists primarily of small mammals (e.g., squirrels, rabbits, and mouse and rat species) and birds, particularly ground-nesting species such as quail [20]. Because of its extreme size and consequent large venom yield, $C$. adamanteus is arguably the most dangerous snake species in the United States and is one of the major sources of snakebite mortality throughout its range [21]. Crotalus adamanteus has recently become of interest from a conservation standpoint because of its declining range, which at one time included seven states along the southeastern Coastal Plain [22]. This species has now apparently been extirpated from Louisiana and is listed as endangered in North Carolina [23,24]. As a consequence of recent work by Rokyta et al. [11] based on 454 pyrosequencing, the venom of $C$. adamanteus is among the best-characterized snake venoms; 40 toxins have been identified.

Transcriptomic characterizations of venom glands of snakes [25-28] and other animals [29-32] have relied almost exclusively on low-throughput sequencing approaches. Sanger sequencing, with its relatively long, high-quality reads, has been the only method available until recently and has provided invaluable data on the identities of venom genes. Because venomous species are primarily nonmodel organisms, high-throughput sequencing approaches have been slow to pervade the field of venomics (but see $\mathrm{Hu}$ et al. [33]), despite becoming commonplace in other transcriptomic-based fields. Rokyta et al. [11] recently used 454 pyrosequencing to characterize venom genes for $C$. adamanteus. More recently, Durban et al. [34] used 454 sequencing to study the venom-gland transcriptomes of a mix of RNA from eight species of Costa Rican snakes. Whittington et al. [30] used a hybrid approach with both 454 and Illumina sequencing to characterize the platypus venom-gland transcriptome, although they had a reference genome sequence, making de novo assembly unnecessary. Pyrosequencing is expensive and low-throughput relative to Illumina sequencing, and the high error rate, particularly for homopolymer errors [35], significantly increases the difficulty of identifying coding sequences without reference sequences.

We sequenced the venom-gland transcriptome of the eastern diamondback rattlesnake with Illumina technology using a paired-end approach coupled with short insert sizes effectively to produce longer, high-quality reads on the order of approximately $150 \mathrm{nt}$ to facilitate de novo assembly (an approach similar to that of Rodrigue et al. [36] for metagenomics). The difference in read length from that of 454 sequencing was compensated for by the increase of more than two orders of magnitude in the number of reads. We demonstrated de novo assembly and analysis of a venom-gland transcriptome using only Illumina sequences and provided a comprehensive characterization of both the toxin and nontoxin genes expressed in an actively producing snake venom gland.

\section{Results and discussion}

\section{Venom-gland transcriptome sequencing and assembly}

We generated a total of $95,643,958$ pairs of reads that passed the Illumina quality filter for $>19$ gigabases $(\mathrm{Gb})$ of sequence from a cDNA library with an average insert size of $\sim 170 \mathrm{nt}$. Of these reads, 72,114,709 (75\%) were merged (see Methods) on the basis of their 3' overlap (Figure 1), yielding composite reads of average length $142 \mathrm{nt}$ with average phred qualities $>40$ and a total length $>10 \mathrm{~Gb}$. This merging of reads reduced the effective size of the data set without loss of information and provided long reads to facilitate accurate assembly.

Our first approach to transcriptome assembly was aimed at identifying toxin genes. We attempted to use as many of the data as possible to ensure the identification of even the lowest-abundance toxins. To this end, we conducted extensive searches of assembly parameter space for both ABySS [37,38] (Table 1) and Velvet [39] on the basis of the full set of both merged and unmerged reads. We used the assemblies with the best N50 values for further analysis. For Velvet, the assembly using a $k$-mer size of 91 was best $(N 50=408)$; this assembly was subsequently analyzed with Oases [40]. For ABySS, the best $k$-mer value 


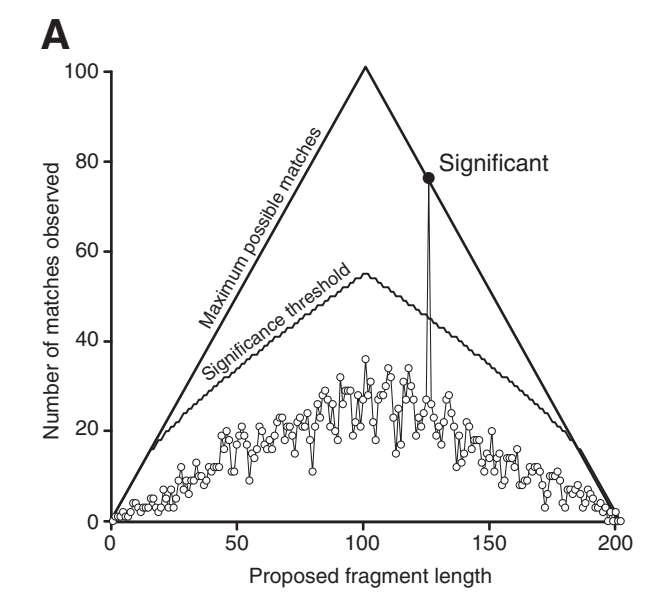

B

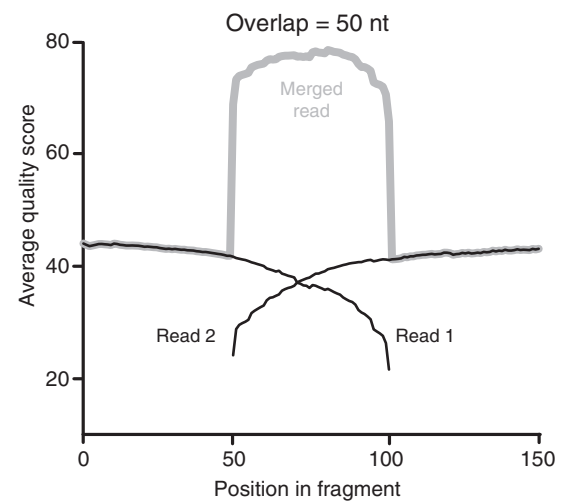

Figure 1 Merging overlapping reads. (A) Reads are slid along each other until the number of matches exceeds the significance threshold. In the example shown, the optimal overlap is 74 nucleotides (nt). (B) The quality of reads declines dramatically toward their $3^{\prime}$ ends, where overlap occurs if the fragment length is less than twice the read length, allowing the actual quality to be much higher than the nominal values. The example shown is the average of pairs that overlap by exactly $50 \mathrm{nt}$.

Table 1 ABySS assembly summaries

\begin{tabular}{|c|c|c|c|c|c|c|c|c|c|c|}
\hline$k$ & $c$ & $e$ & $\begin{array}{c}\text { Total } \\
\text { contigs }\end{array}$ & $\begin{array}{c}\text { Longest } \\
\text { contig }\end{array}$ & $\begin{array}{l}\text { Contigs } \\
>200 \mathrm{nt}\end{array}$ & $\begin{array}{l}\text { Contigs } \\
>\text { N50 }\end{array}$ & Median & Mean & N50 & $\begin{array}{l}\text { Total } \\
\text { length }\end{array}$ \\
\hline 51 & 2 & 2 & $2,168,050$ & 15,079 & 147,942 & 27,410 & 364 & 592 & 790 & $8.77 \times 10^{7}$ \\
\hline 51 & 10 & 2 & 329,609 & 17,493 & 37,575 & 6,399 & 571 & 985 & 1,635 & $3.70 \times 10^{7}$ \\
\hline 51 & 10 & 10 & 337,039 & 17,459 & 37,944 & 6,390 & 554 & 967 & 1,621 & $3.67 \times 10^{7}$ \\
\hline 51 & 20 & 20 & 191,367 & 15,906 & 27,546 & 4,931 & 529 & 878 & 1,401 & $2.42 \times 10^{7}$ \\
\hline 51 & 30 & 30 & 135,961 & 13,472 & 21,986 & 4,034 & 494 & 812 & 1,256 & $1.79 \times 10^{7}$ \\
\hline 51 & 50 & 50 & 87,092 & 10,380 & 15,461 & 2,955 & 463 & 737 & 1,088 & $1.14 \times 10^{7}$ \\
\hline 51 & 100 & 10 & 42,366 & 8,553 & 8,510 & 1,725 & 432 & 658 & 906 & $5.60 \times 10^{6}$ \\
\hline 51 & 100 & 100 & 42,251 & 8,552 & 8,401 & 1,707 & 431 & 656 & 899 & $5.52 \times 10^{6}$ \\
\hline 51 & 1000 & 1000 & 2,319 & 5,232 & 571 & 123 & 428 & 631 & 797 & $3.61 \times 10^{5}$ \\
\hline 61 & 2 & 2 & $1,769,274$ & 17,166 & 141,471 & 25,105 & 361 & 604 & 827 & $8.55 \times 10^{7}$ \\
\hline 61 & 10 & 2 & 263,688 & 17,493 & 34,076 & 5,959 & 618 & 1,032 & 1,691 & $3.52 \times 10^{7}$ \\
\hline 61 & 10 & 10 & 272,814 & 17,459 & 35,002 & 6,036 & 586 & 998 & 1,651 & $3.50 \times 10^{7}$ \\
\hline 61 & 20 & 20 & 154,459 & 15,906 & 25,114 & 4,575 & 545 & 891 & 1,408 & $2.24 \times 10^{7}$ \\
\hline 61 & 30 & 30 & 109,994 & 10,070 & 19,994 & 3,721 & 496 & 808 & 1,232 & $1.62 \times 10^{7}$ \\
\hline 61 & 50 & 50 & 70,029 & 10,349 & 13,916 & 2,675 & 455 & 725 & 1,073 & $1.01 \times 10^{7}$ \\
\hline 61 & 100 & 10 & 32,476 & 8,300 & 7,318 & 1,479 & 426 & 655 & 894 & $4.79 \times 10^{6}$ \\
\hline 61 & 100 & 100 & 32,392 & 7,822 & 7,231 & 1,463 & 423 & 652 & 893 & $4.72 \times 10^{6}$ \\
\hline 61 & 1000 & 1000 & 1,709 & 5,209 & 531 & 114 & 424 & 614 & 798 & $3.27 \times 10^{5}$ \\
\hline 71 & 2 & 2 & $1,431,412$ & 15,641 & 131,742 & 22,422 & 360 & 617 & 870 & $8.13 \times 10^{7}$ \\
\hline 71 & 10 & 2 & 208,036 & 17,484 & 29,793 & 5,393 & 683 & 1,101 & 1,785 & $3.28 \times 10^{7}$ \\
\hline 71 & 10 & 10 & 219,099 & 17,432 & 31,400 & 5,567 & 629 & 1,041 & 1,705 & $3.27 \times 10^{7}$ \\
\hline 71 & 20 & 20 & 122,216 & 14,372 & 21,816 & 4,052 & 581 & 928 & 1,460 & $2.03 \times 10^{7}$ \\
\hline 71 & 30 & 30 & 86,599 & 10,416 & 17,138 & 3,249 & 524 & 835 & 1,272 & $1.43 \times 10^{7}$ \\
\hline 71 & 50 & 50 & 54,694 & 10,341 & 11,925 & 2,313 & 464 & 729 & 1,075 & $8.70 \times 10^{6}$ \\
\hline 71 & 100 & 10 & 23,980 & 7,817 & 6,183 & 1,253 & 424 & 650 & 892 & $4.02 \times 10^{6}$ \\
\hline
\end{tabular}


Table 1 ABySS assembly summaries (Continued)

\begin{tabular}{ccccccccccc}
\hline 71 & 100 & 100 & 23,997 & 7,810 & 6,119 & 1,239 & 419 & 644 & 889 & $3.95 \times 10^{6}$ \\
71 & 1000 & 1000 & 1,199 & 5,202 & 443 & 87 & 444 & 660 & 885 & $2.93 \times 10^{5}$ \\
81 & 2 & 2 & $1,142,924$ & 15,303 & 120,593 & 19,697 & 354 & 625 & 911 & $7.54 \times 10^{7}$ \\
81 & 10 & 2 & 158,781 & 17,713 & 24,939 & 4,721 & 788 & 1,202 & 1,898 & $3.00 \times 10^{7}$ \\
81 & 10 & 10 & 174,032 & 17,688 & 27,366 & 5,005 & 691 & 1,096 & 1,774 & $3.00 \times 10^{7}$ \\
81 & 20 & 20 & 92,627 & 15,784 & 17,715 & 3,396 & 654 & 1,011 & 1,573 & $1.79 \times 10^{7}$ \\
81 & 30 & 30 & 64,866 & 9,868 & 13,697 & 2,666 & 592 & 904 & 1,366 & $1.24 \times 10^{7}$ \\
81 & 50 & 50 & 39,613 & 10,328 & 9,358 & 1,874 & 513 & 778 & 1,130 & $7.28 \times 10^{6}$ \\
81 & 100 & 10 & 16,303 & 10,149 & 4,777 & 970 & 454 & 687 & 963 & $3.28 \times 10^{6}$ \\
81 & 100 & 100 & 16,493 & 10,155 & 4,817 & 981 & 438 & 671 & 943 & $3.23 \times 10^{6}$ \\
81 & 1000 & 1000 & 889 & 5,198 & 381 & 82 & 454 & 649 & 790 & $2.47 \times 10^{5}$ \\
91 & 2 & 2 & 932,237 & 15,694 & 108,954 & 17,394 & 344 & 622 & 936 & $6.79 \times 10^{7}$ \\
91 & 10 & 2 & 124,647 & 17,713 & 20,420 & 4,025 & 880 & 1,293 & 2,007 & $2.64 \times 10^{7}$ \\
91 & 10 & 10 & 142,306 & 17,687 & 23,525 & 4,428 & 727 & 1,126 & 1,804 & $2.65 \times 10^{7}$ \\
91 & 20 & 20 & 72,117 & 15,792 & 13,614 & 2,702 & 752 & 1,108 & 1,712 & $1.51 \times 10^{7}$ \\
91 & 30 & 30 & 48,540 & 15,792 & 9,949 & 2,009 & 700 & 1,023 & 1,529 & $1.02 \times 10^{7}$ \\
91 & 50 & 50 & 27,581 & 10,199 & 6,477 & 1,336 & 624 & 901 & 1,309 & $5.84 \times 10^{6}$ \\
91 & 100 & 10 & 10,503 & 10,105 & 3,081 & 658 & 564 & 816 & 1,155 & $2.52 \times 10^{6}$ \\
91 & 100 & 100 & 10,770 & 10,149 & 3,308 & 705 & 528 & 769 & 1,078 & $2.54 \times 10^{6}$ \\
91 & 1000 & 1000 & 598 & 3,008 & 342 & 76 & 438 & 621 & 754 & $2.12 \times 10^{5}$ \\
\hline & 100 & & & & & & & & &
\end{tabular}

was also $91(N 50=2,007)$, but because the performance in terms of full-length transcripts appeared to depend strongly on the coverage $(c)$ and erode $(e)$ parameters, we further analyzed the $k=91$ assemblies with $c=10$ and $e=2, c=100$ and $e=100$, and $c=1000$ and $e=1000$. We identified all full-length toxins by means of blastx searches on the results of all four assemblies.

As part of our first approach, we also performed four independent de novo transcriptome assemblies with NGen: three with 20 million merged reads each and one with the remaining 12,114,709 merged reads (Table 2). We identified all full-length toxins from all four assemblies. Given that all three assembly methods tended to generate a large number of fragmented toxin sequences, apparently because of retained introns and possibly alternative splicing, we developed and implemented a simple hash-table approach to completing partial transcripts, which we will refer to as Extender (see Methods). We used Extender on partial toxin sequences identified for two of the four NGen assemblies. We also annotated the most abundant fulllength nontoxin transcripts for the three assemblies based on 20 million reads. After combining all of the annotated toxin and nontoxin sequences from the ABySS, Velvet, and NGen assemblies and eliminating duplicates, we had 72 unique toxin sequences and 234 unique nontoxin sequences. The paucity of full-length annotated nontoxins reflects our focus on toxin sequences rather than their absence in the assemblies.

Our second approach to transcriptome assembly was designed to annotate as many full-length coding sequences (toxin and nontoxin) as possible and to build a reference database of sequences to facilitate the future

Table 2 NGen assembly summaries

\begin{tabular}{|c|c|c|c|c|c|c|}
\hline Assembly & No. reads & No. contigs & $\begin{array}{c}\text { No. contigs } \\
>2 \mathrm{k}\end{array}$ & $\begin{array}{l}\text { Assembled } \\
\text { sequences }\end{array}$ & $\begin{array}{l}\text { Unique full- } \\
\text { length toxins }\end{array}$ & $\begin{array}{l}\text { Unique Extender } \\
\text { toxins }\end{array}$ \\
\hline NGen 1 & $20,000,000$ & 12,694 & 4,403 & $9,786,054$ & 34 & 54 \\
\hline NGen 2 & $20,000,000$ & 12,746 & 4,439 & $9,821,212$ & 36 & 54 \\
\hline NGen 3 & $20,000,000$ & 12,698 & 4,412 & $9,820,553$ & 38 & - \\
\hline NGen 4 & $12,114,709$ & 8,484 & 3,078 & $5,948,003$ & 34 & - \\
\hline \multicolumn{6}{|c|}{ Total unique full-length toxins = } & 154 \\
\hline
\end{tabular}


analysis of other snake venom-gland transcriptomes. We found that NGen was much more successful at producing transcripts with full-length coding sequences but also that it was quite inefficient when the coverage distribution was extremely uneven (see Figure 2). Feldmeyer et al. [41] also found NGen to have the best assembly performance with Illumina data. We sought therefore first to eliminate the transcripts and corresponding reads for the extremely high-abundance sequences. To do so, we employed Extender as a de novo assembler by starting from 1,000 individual high-quality reads and attempting to complete their transcripts (see Methods). From 1,000 seeds, we identified 318 full-length coding sequences with 213 toxins and 105 nontoxins. After duplicates were eliminated, this procedure resulted in 58 unique toxin and 44 unique nontoxin full-length transcripts. These sequences were used to filter the corresponding reads from the full set of merged reads with NGen. We then performed a de

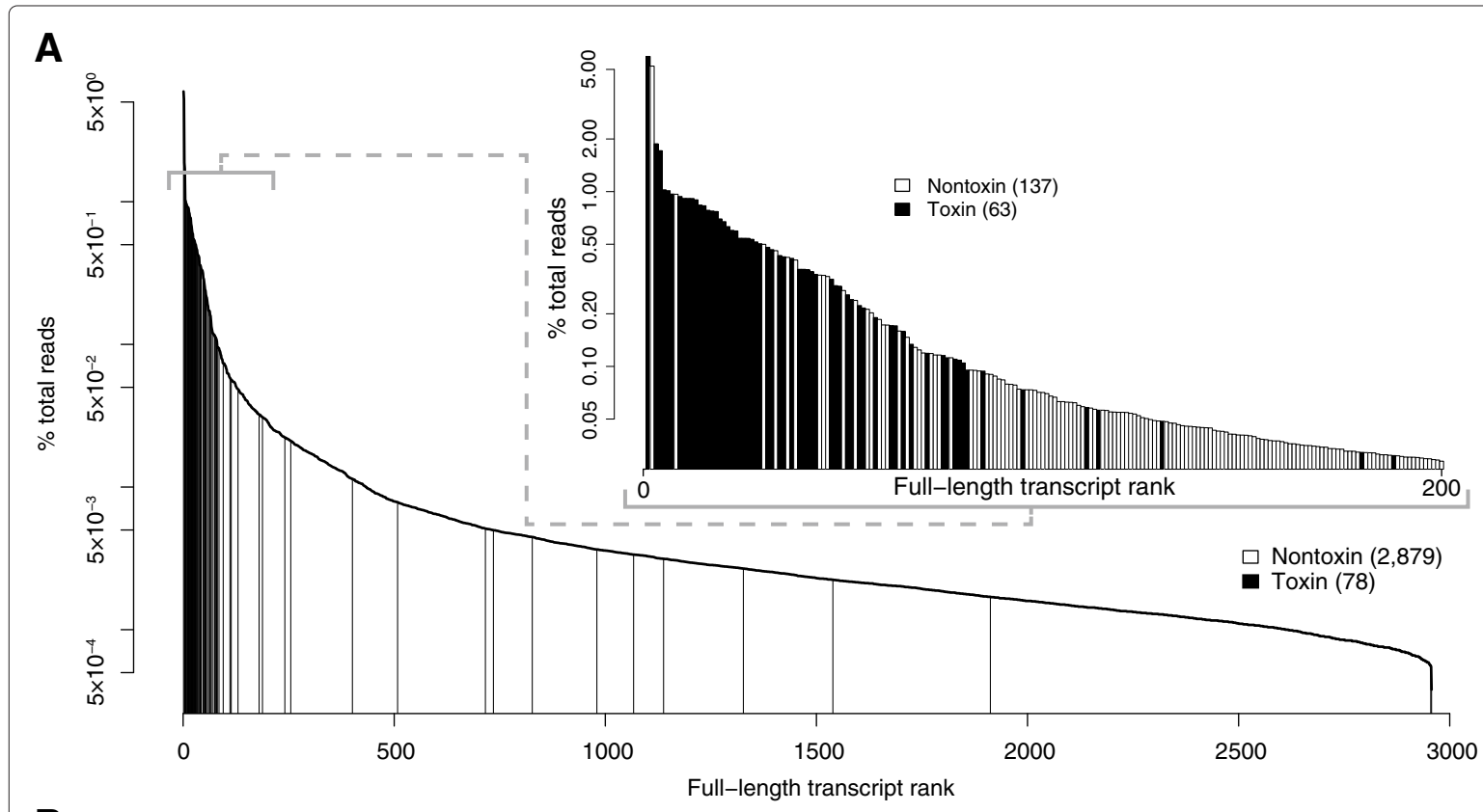

B

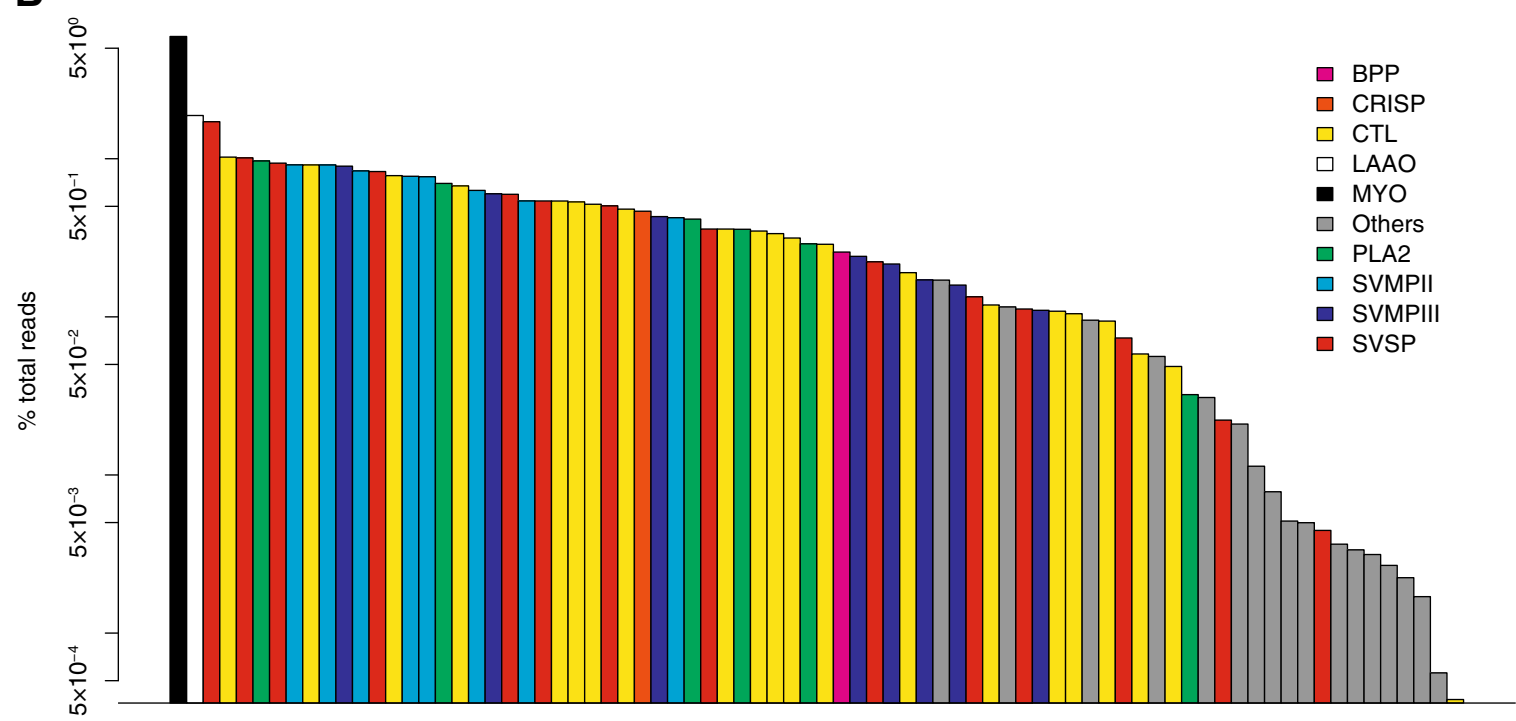

Toxin clusters

Figure 2 Domination of the $\boldsymbol{C}$. adamanteus venom-gland transcriptome by toxin transcripts. The 123 unique toxin sequences were clustered into 78 groups with less than $1 \%$ nucleotide divergence for estimation of abundances. (A) The vast majority of the extremely highly expressed genes were toxins. The inset shows a magnification of the top 200 transcripts. (B) Expression levels of individual toxin clusters are shown with toxin classes coded by color. The toxin clusters are in the same order as in Table 3. 
novo transcriptome assembly on 10 million of the filtered reads with NGen, annotated full-length transcripts from contigs comprising $\geq 200$ reads with significant blastx hits, and used the resulting unique sequences as a new filter. This process of assembly, annotation, and filtering was iterated two more times. The end result was 91 unique toxin and 2,851 unique nontoxin sequences.

The results from both assembly approaches were merged to yield the final data set. The first approach produced 72 unique toxin and 234 unique nontoxin sequences, and the second 91 toxin and 2,851 nontoxin sequences. The merged data set consisted of 123 unique toxin sequences and 2,879 nontoxins that together accounted for $62.9 \%$ of the sequencing reads (Figure 3).

\section{Toxin transcripts}

We identified 123 individual, unique toxin transcripts with full-length coding sequences. To estimate the abundances of these transcripts in the $C$. adamanteus venom-gland transcriptome, we clustered them into 78 groups with less than $1 \%$ nt divergence (Table 3). Clusters could include alleles, recent duplicates, or even sequencing errors, which are characteristic of high-throughput sequencing [42]. For longer genes, clusters might also include different combinations of variable sites that are widely separated in the sequence. We chose $1 \%$ as a practical, but arbitrary, cut-off for defining clusters. Mapping reads back to more similar sequences to estimate abundances would be problematic because reads could not be uniquely assigned to a particular sequence. The true number of toxin genes
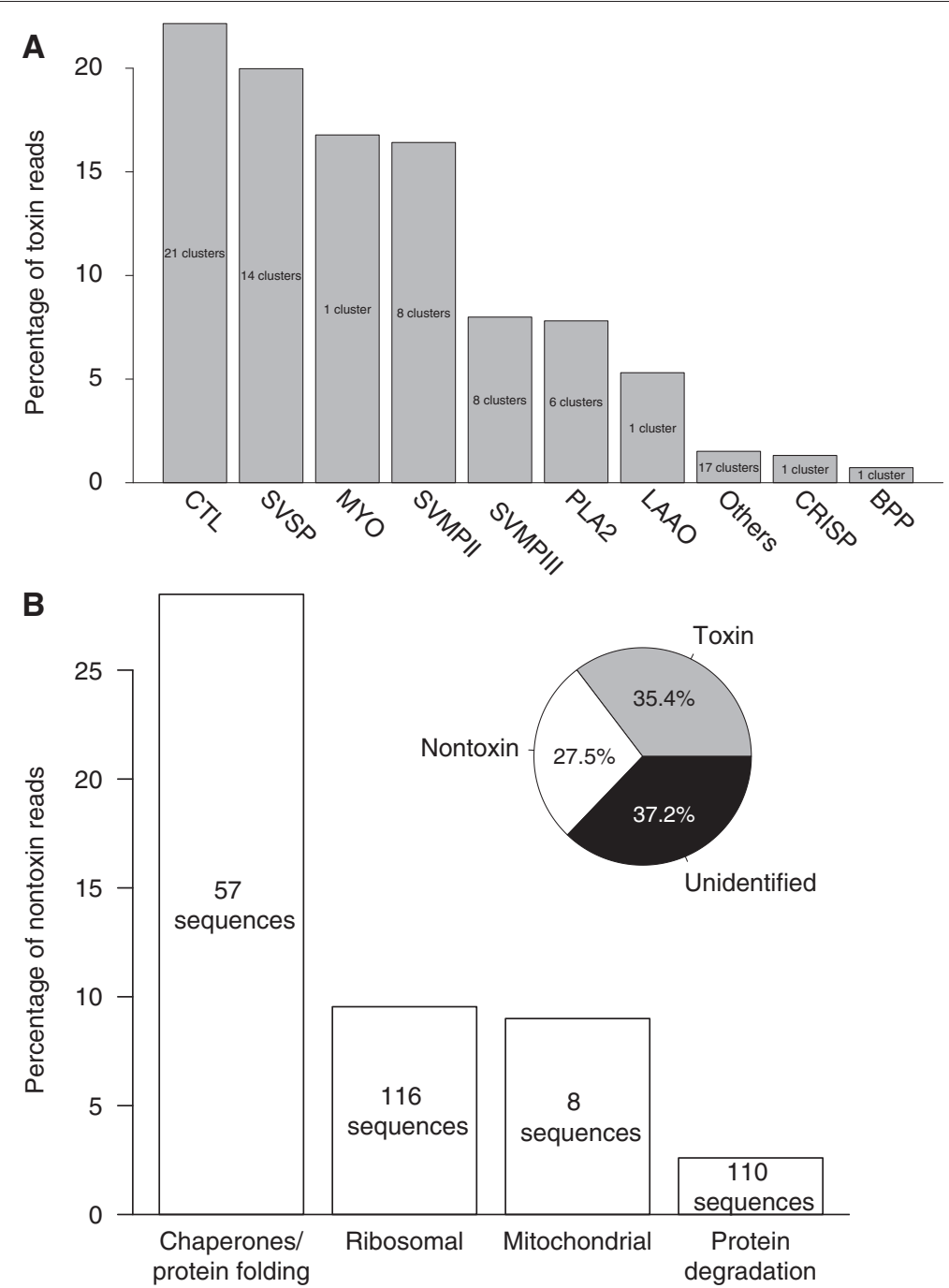

Figure 3 Expression levels of major classes of toxins and nontoxins. More than $60 \%$ of the total reads have been accounted for with full-length annotated transcripts. (A) The major toxin classes were the CTLS, SVSPS, MYO, and SVMPs (types II and III). (B) As expected for a protein-secreting tissue, the venom gland expresses an abundance of proteins involved in proteostasis. 
Table 3 Expression levels of full-length toxin clusters

\begin{tabular}{|c|c|c|c|c|c|c|}
\hline Rank & Cluster name & Cluster size & Length & $\%$ total reads & $\%$ toxin reads & GenBank TSA accessions \\
\hline 1 & MYO & 1 & 994 & 5.93 & 16.780 & JU173668 \\
\hline 2 & LAAO & 1 & 3089 & 1.88 & 5.309 & JU173667 \\
\hline 3 & SVSP-6 & 1 & 1720 & 1.71 & 4.849 & JU173733 \\
\hline \multirow[t]{3}{*}{4} & $C T L-8$ & 3 & 721 & 1.02 & 2.896 & a:JU173656, \\
\hline & & & & & & b:JU173657, \\
\hline & & & & & & c:JU173658 \\
\hline 5 & SVSP-13 & 1 & 1661 & 1.01 & 2.864 & JU173724 \\
\hline \multirow[t]{2}{*}{6} & PLA2-1 & 2 & 904 & $9.68 \times 10^{-1}$ & 2.739 & a:JU173675, \\
\hline & & & & & & b:JU173676 \\
\hline \multirow[t]{2}{*}{7} & SVSP-3 & 2 & 1830 & $9.38 \times 10^{-1}$ & 2.653 & a:JU173728, \\
\hline & & & & & & b:JU173729 \\
\hline \multirow[t]{8}{*}{8} & SVMPII-5 & 8 & 2124 & $9.15 \times 10^{-1}$ & 2.587 & a:JU173694, \\
\hline & & & & & & b:JU173695, \\
\hline & & & & & & c:JU173696, \\
\hline & & & & & & d:JU173697, \\
\hline & & & & & & e:JU173698, \\
\hline & & & & & & f:JU173699, \\
\hline & & & & & & g:JU173700, \\
\hline & & & & & & h:JU173701 \\
\hline \multirow[t]{5}{*}{9} & CTL-4 & 5 & 780 & $9.14 \times 10^{-1}$ & 2.585 & a:JU173646, \\
\hline & & & & & & b:JU173647, \\
\hline & & & & & & c:JU173648, \\
\hline & & & & & & d:JU173649, \\
\hline & & & & & & e:JU173650 \\
\hline \multirow[t]{5}{*}{10} & SVMPII-1 & 5 & 2298 & $9.13 \times 10^{-1}$ & 2.583 & a:JU173682, \\
\hline & & & & & & b:JU173683, \\
\hline & & & & & & c:JU173684, \\
\hline & & & & & & d:JU173685, \\
\hline & & & & & & e:JU173686 \\
\hline \multirow[t]{5}{*}{11} & SVMPIII-2 & 5 & 2246 & $8.97 \times 10^{-1}$ & 2.538 & a:JU173707, \\
\hline & & & & & & b:JU173708, \\
\hline & & & & & & c:JU173709, \\
\hline & & & & & & d:JU173710, \\
\hline & & & & & & e:JU173711 \\
\hline \multirow[t]{2}{*}{12} & SVMPII-2 & 2 & 2138 & $8.38 \times 10^{-1}$ & 2.369 & a:JU173687, \\
\hline & & & & & & b:JU173688 \\
\hline 13 & SVSP-1 & 1 & 3120 & $8.30 \times 10^{-1}$ & 2.348 & JU173726 \\
\hline 14 & CTL-16 & 1 & 711 & $7.82 \times 10^{-1}$ & 2.211 & JU173631 \\
\hline 15 & SVMPII-7 & 1 & 2082 & $7.74 \times 10^{-1}$ & 2.191 & JU173703 \\
\hline \multirow[t]{4}{*}{16} & SVMPII-3 & 4 & 1931 & $7.69 \times 10^{-1}$ & 2.176 & a:JU173689, \\
\hline & & & & & & b:JU173690, \\
\hline & & & & & & c:JU173691, \\
\hline & & & & & & d:JU173692 \\
\hline 17 & PLA2-4 & 1 & 890 & $6.98 \times 10^{-1}$ & 1.974 & JU173679 \\
\hline
\end{tabular}


Table 3 Expression levels of full-length toxin clusters (Continued)

\begin{tabular}{|c|c|c|c|c|c|c|}
\hline \multirow{6}{*}{18} & CTL-3 & 6 & 797 & $6.73 \times 10^{-1}$ & 1.905 & a:JU173640, \\
\hline & & & & & & b:JU173641, \\
\hline & & & & & & c:JU173642, \\
\hline & & & & & & d:JU173643, \\
\hline & & & & & & e:JU173644, \\
\hline & & & & & & f:JU173645 \\
\hline 19 & SVMPII-6 & 1 & 2183 & $6.31 \times 10^{-1}$ & 1.784 & JU173702 \\
\hline \multirow[t]{3}{*}{20} & SVMPIII-3 & 3 & 2401 & $6.00 \times 10^{-1}$ & 1.698 & a:JU173712, \\
\hline & & & & & & b:JU173713, \\
\hline & & & & & & c:JU173714 \\
\hline 21 & SVSP-9 & 1 & 10270 & $5.96 \times 10^{-1}$ & 1.685 & JU173738 \\
\hline 22 & SVMPII-4 & 1 & 2016 & $5.41 \times 10^{-1}$ & 1.530 & JU173693 \\
\hline 23 & SVSP-8 & 1 & 3524 & $5.41 \times 10^{-1}$ & 1.529 & JU173737 \\
\hline 24 & CTL-7 & 1 & 763 & $5.40 \times 10^{-1}$ & 1.528 & JU173655 \\
\hline 25 & CTL-18 & 1 & 775 & $5.33 \times 10^{-1}$ & 1.509 & JU173633 \\
\hline 26 & CTL-1 & 1 & 763 & $5.15 \times 10^{-1}$ & 1.458 & JU173635 \\
\hline 27 & SVSP-12 & 1 & 957 & $5.04 \times 10^{-1}$ & 1.424 & JU173723 \\
\hline 28 & CTL-6 & 1 & 607 & $4.80 \times 10^{-1}$ & 1.358 & JU173654 \\
\hline 29 & CRISP & 1 & 1579 & $4.66 \times 10^{-1}$ & 1.317 & JU173623 \\
\hline 30 & SVMPIII-7 & 1 & 2343 & $4.31 \times 10^{-1}$ & 1.218 & JU173719 \\
\hline 31 & SVMPII-8 & 1 & 1863 & $4.24 \times 10^{-1}$ & 1.198 & JU173704 \\
\hline 32 & PLA2-6 & 1 & 834 & $4.15 \times 10^{-1}$ & 1.174 & JU173681 \\
\hline \multirow[t]{3}{*}{33} & SVSP-7 & 3 & 2108 & $3.59 \times 10^{-1}$ & 1.016 & a:JU173734, \\
\hline & & & & & & b:JU173735, \\
\hline & & & & & & c:JU173736 \\
\hline 34 & CTL-15 & 1 & 947 & $3.59 \times 10^{-1}$ & 1.016 & JU173630 \\
\hline 35 & PLA2-2 & 1 & 872 & $3.58 \times 10^{-1}$ & 1.013 & JU173677 \\
\hline 36 & CTL-10 & 1 & 587 & $3.49 \times 10^{-1}$ & 0.987 & JU173624 \\
\hline 37 & CTL-14 & 1 & 1246 & $3.36 \times 10^{-1}$ & 0.951 & JU173629 \\
\hline 38 & CTL-13 & 1 & 680 & $3.15 \times 10^{-1}$ & 0.891 & JU173628 \\
\hline 39 & PLA2-5 & 1 & 651 & $2.90 \times 10^{-1}$ & 0.819 & JU173680 \\
\hline \multirow[t]{2}{*}{40} & CTL-9 & 2 & 755 & $2.88 \times 10^{-1}$ & 0.814 & a:JU173659, \\
\hline & & & & & & b:JU173660 \\
\hline 41 & BPP & 1 & 1300 & $2.57 \times 10^{-1}$ & 0.726 & JU173621 \\
\hline \multirow[t]{2}{*}{42} & SVMPIII-1 & 2 & 2665 & $2.41 \times 10^{-1}$ & 0.683 & a:JU173705, \\
\hline & & & & & & b:JU173706 \\
\hline 43 & SVSP-14 & 1 & 1732 & $2.23 \times 10^{-1}$ & 0.631 & JU173725 \\
\hline \multirow[t]{2}{*}{44} & SVMPIII-4 & 2 & 2433 & $2.16 \times 10^{-1}$ & 0.611 & a:JU173715, \\
\hline & & & & & & b:JU173716 \\
\hline \multirow[t]{2}{*}{45} & $C T L-2$ & 2 & 749 & $1.90 \times 10^{-1}$ & 0.538 & a:JU173638, \\
\hline & & & & & & b:JU173639 \\
\hline 46 & SVMPIII-8 & 1 & 2150 & $1.71 \times 10^{-1}$ & 0.484 & JU173720 \\
\hline 47 & VESP & 1 & 1603 & $1.71 \times 10^{-1}$ & 0.483 & JU173741 \\
\hline 48 & SVMPIII-5 & 1 & 2339 & $1.59 \times 10^{-1}$ & 0.449 & JU173717 \\
\hline
\end{tabular}


Table 3 Expression levels of full-length toxin clusters (Continued)

\begin{tabular}{|c|c|c|c|c|c|c|}
\hline 49 & SVSP-4 & 2 & 2152 & $1.34 \times 10^{-1}$ & 0.379 & $\begin{array}{l}\text { a:JU173730, } \\
\text { b:JU173731 }\end{array}$ \\
\hline 50 & CTL-20 & 1 & 785 & $1.19 \times 10^{-1}$ & 0.336 & JU173636 \\
\hline 51 & NUC & 1 & 2706 & $1.16 \times 10^{-1}$ & 0.327 & JU173671 \\
\hline 52 & SVSP-5 & 1 & 1890 & $1.12 \times 10^{-1}$ & 0.317 & JU173732 \\
\hline 53 & SVMPIII-6 & 1 & 2367 & $1.10 \times 10^{-1}$ & 0.311 & JU173718 \\
\hline 54 & CTL-21 & 1 & 824 & $1.09 \times 10^{-1}$ & 0.307 & JU173637 \\
\hline 55 & CTL-19 & 1 & 618 & $1.05 \times 10^{-1}$ & 0.296 & JU173634 \\
\hline 56 & NF & 1 & 1395 & $9.53 \times 10^{-2}$ & 0.269 & JU173669 \\
\hline 57 & CTL-12 & 2 & 825 & $9.40 \times 10^{-2}$ & 0.266 & a:JU173626, \\
\hline & & & & & & b:JU173627 \\
\hline 58 & SVSP-2 & 1 & 1675 & $7.35 \times 10^{-2}$ & 0.208 & JU173727 \\
\hline 59 & CTL-5 & 3 & 637 & $5.83 \times 10^{-2}$ & 0.165 & a:JU173651, \\
\hline & & & & & & b:JU173652, \\
\hline & & & & & & c:JU173653 \\
\hline 60 & PDE & 1 & 2743 & $5.62 \times 10^{-2}$ & 0.159 & JU173674 \\
\hline 61 & CTL-11 & 1 & 625 & $4.86 \times 10^{-2}$ & 0.137 & JU173625 \\
\hline 62 & PLA2-3 & 1 & 957 & $3.22 \times 10^{-2}$ & 0.091 & JU173678 \\
\hline 63 & CREGF & 1 & 1945 & $3.09 \times 10^{-2}$ & 0.087 & JU173622 \\
\hline 64 & SVSP-10 & 1 & 1815 & $2.22 \times 10^{-2}$ & 0.063 & JU173721 \\
\hline 65 & HYAL-1 & 1 & 2545 & $2.10 \times 10^{-2}$ & 0.059 & JU173662 \\
\hline 66 & KUN & 1 & 1698 & $1.14 \times 10^{-2}$ & 0.032 & JU173666 \\
\hline 67 & HYAL-2 & 1 & 1302 & $7.83 \times 10^{-3}$ & 0.022 & JU173663 \\
\hline 68 & KUN-1 & 1 & 2575 & $5.11 \times 10^{-3}$ & 0.014 & JU173664 \\
\hline 69 & VEGF-1 & 2 & 906 & $4.99 \times 10^{-3}$ & 0.014 & a:JU173739, \\
\hline & & & & & & b:JU173740 \\
\hline 70 & SVSP-11 & 1 & 1207 & $4.46 \times 10^{-3}$ & 0.013 & JU173722 \\
\hline 71 & GC & 1 & 1730 & $3.65 \times 10^{-3}$ & 0.010 & JU173661 \\
\hline 72 & PDE-6 & 1 & 3691 & $3.36 \times 10^{-3}$ & 0.010 & JU173673 \\
\hline 73 & NGF & 1 & 951 & $3.14 \times 10^{-3}$ & 0.009 & JU173670 \\
\hline 74 & KUN-2 & 1 & 1438 & $2.68 \times 10^{-3}$ & 0.008 & JU173665 \\
\hline 75 & PDE-4 & 1 & 2633 & $2.24 \times 10^{-3}$ & 0.006 & JU173672 \\
\hline 76 & VF & 1 & 5087 & $1.70 \times 10^{-3}$ & 0.005 & JU173742 \\
\hline 77 & WAP & 1 & 627 & $5.60 \times 10^{-4}$ & 0.002 & JU173743 \\
\hline 78 & CTL-17 & 1 & 774 & $3.80 \times 10^{-4}$ & 0.001 & JU173632 \\
\hline
\end{tabular}

for $C$. adamanteus probably lies somewhere between 78 and 123. This range is at the lower end of the number of unique toxins typically identified for viperids by means of proteomic techniques [10], which may indicate that the venom of $C$. adamanteus is less complex than that of other species. Alternatively, posttranscriptional processes such as alternative splicing or posttranslational modifications could significantly increase the diversity of toxins present in the venom. Our identified toxins accounted for $35.4 \%$ of the total reads (Figure 3 ), and the vast majority of the extremely high-abundance transcripts were those encoding toxin proteins (Figure 2A). We named toxins with a combination of a toxin-class abbreviation, a cluster number, and, if the cluster had more than a single member, a lower-case letter to indicate the member of the cluster (e.g., CTL-3b).

We used the number or percentage of reads mapping to a particular transcript as a measure of its abundance. Although average coverage might be a more appropriate proxy for the number of copies of a given transcript 
present, because it accounts for differences in transcript lengths, we prefer read counts as a measure of the expression expenditure on a given transcript because they better reflect the energetic cost associated with producing the encoded protein and are consistent with previous work using low-throughput sequencing (see, e.g., Pahari et al. [25]). In addition, this measurement should more closely match proteomic-based measurements of the contents of venom components (see, e.g., Gibbs et al. [43]) which come in the form of the percentages of total peptide bonds in the sample.

\section{Snake venom metalloproteinases}

We identified 39 unique sequences and 16 clusters of snake-venom metalloproteinases (SVMPs) that accounted for $24.4 \%$ of the reads mapping to toxin sequences and $8.6 \%$ of the total reads (Figure $3 \mathrm{~A}$ and Table 3 ). In terms of total reads, the SVMPs were the most abundant class of toxins in the C. adamanteus venom-gland transcriptome. SVMPs are the primary sources of the local and systemic hemorrhage associated with envenomation by viperids and are divided into a number of subclasses based on their domain structure $[44,45]$. All SVMPs have a metalloproteinase domain characterized by a zinc-binding motif. All of the SVMPs identified for C. adamanteus belong to either the type II or the type III subclass. Type II SVMPs (SVMPIIs) have a disintegrin domain in addition to the metalloproteinase domain, which may be proteolytically cleaved posttranslationally to produce a free disintegrin. Type III SVMPs (SVMPIIIs) have a disintegrin-like and a cysteine-rich domain in addition to the metalloproteinase domain. We found 8 clusters of each of these two subclasses with 23 unique SVMPII sequences and 16 unique SVMPIII sequences. SVMPII and SVMPIII clusters comprise $16.4 \%$ and $8.0 \%$ of the reads mapping to toxins respectively (Figure 3 ). The sequences in both subclasses are diverse. The maximum pairwise nt divergence for the SVMPIIs was $10.0 \%$, corresponding to a maximum aminoacid divergence of $18.1 \%$. For the SVMPIIIs, the maximum pairwise nt divergence was $20.4 \%$ with a maximum amino-acid divergence of $42.3 \%$. Although SVMPs were the dominant toxins as a class, the individual SVMP cluster with the highest abundance was SVMPII-5, which was only the eighth most abundant toxin cluster (Figure 2B and Table 3).

Mackessy [46] categorized rattlesnake venoms as type I or type II on the basis of their toxicities and metalloproteinase activities. These two measurements tend to be inversely related in rattlesnakes: species (or populations) with low $\mathrm{LD}_{50}$ values tend also to have low or undetectable hemorrhagic activities. SVMPs are the major hemorrhagic components of snake venoms, and high toxicity appears to be caused mostly by neurotoxic venom components. Low-toxicity venoms with high metalloproteinase activity are classified as type I, and high-toxicity venoms with low metalloproteinase activity are classified as type II. On the basis of the abundance of SVMPs in the venom-gland transcriptome, C. adamanteus clearly has type I venom, although the relatively low toxicity of its venom [46] is at least partially compensated for by its large size and venom yield.

\section{C-type lectins}

The most diverse and the second most abundant toxin class in the $C$. adamanteus venom-gland transcriptome was the C-type lectin (CTL) class. We identified 37 unique sequences and 21 clusters of CTLs that accounted for $22.2 \%$ of the reads mapping to toxins and $7.8 \%$ of the total reads (Figure 3A and Table 3). CTLs generally either inhibit or activate components of plasma or blood-cell types, thereby interfering with hemostasis [47]. Most known snake-venom CTLs function as heterodimers or even more complex arrangements [48], probably accounting in part for their diversity. The divergence among members of this class within the $C$. adamanteus genome was extreme, although all members preserved a CTL-like domain. Some pairs shared virtually no conserved aminoacid positions. Three of the CTL clusters provide evidence for the relevance of alternative splicing in the generation of toxin proteins. CTL-3f, CTL-4e, and CTL9b all have 48nt insertions in the same region but are otherwise similar or identical to other members of their clusters.

\section{Snake venom serine proteinases}

The third most abundant toxin class for C. adamanteus was the snake-venom serine proteinases (SVSPs). We identified 18 unique sequences and 14 clusters in this toxin class, accounting for $20.0 \%$ of the toxin reads and $7.1 \%$ of the total reads (Figure 3A and Table 3). Three of the 10 most highly expressed individual toxins were SVSPs (Figure 2). SVSPs interfere with a wide array of reactions involving blood coagulation and hemostasis and belong to the trypsin family of serine proteases [49,50]. Mackessy [46] detected significant thrombin-like and kallikreinlike activity in the venom of $C$. adamanteus, which are attributable to the action of SVSPs. The diversity of SVSPs within the C. adamanteus genome is high; maximum pairwise nt divergence is $20.6 \%$ and amino-acid divergence is $47.4 \%$.

The members of two SVSP clusters differ in a way that should be noted. The lengths of SVSPs are generally well conserved throughout the class. SVSP-7a has a 27-nt insertion relative to the two other members of its cluster but is otherwise identical to SVSP-7b. This difference could reflect the presence of alternative splicing for this gene. SVSP-3a is unique among the C. adamanteus SVSPs or those known from other snake species in apparently having a 65-amino-acid extension of its C-terminal 
region. The other member of its cluster, SVSP-3b, has a single deletion of a $\mathrm{C} n$ t in a poly- $\mathrm{C}$ tract that terminates its coding sequence consistently with other known SVSPs. The reads generating the SVSP-3a form vastly outnumber those for the SVSP-3b form; more than $95 \%$ of the reads support the extended version of the protein. The effect, if any, of this C-terminal extension remains to be determined.

\section{Phospholipase $A_{2}$ 's}

Previous work with C. adamanteus identified only a single phospholipase $A_{2}$ (PLA2) sequence [11], but we identifed seven unique sequences in six clusters (Figure 2 and Table 3), accounting for $7.8 \%$ of the toxin reads and $2.8 \%$ of the total reads (Figure 3). PLA2s are among the most functionally diverse classes of snake-venom toxins and have pharmocological effects ranging from neurotoxicity (presynaptic or postsynaptic) to myotoxicity and cardiotoxicity. Anticoagulant and hemolytic effects due to PLA2s are also known [51,52]. Compared to other toxin classes of C. adamanteus, the diversity of PLA2s is low. Five of the six clusters are all within 5\% nt divergence of one another. PLA2-3 is the lone, high-divergence outlier, differing by more than $31 \%$ at the nt level from the other clusters. PLA2-3 is also expressed at the lowest level of any of the PLA2s (Table 3).

\section{Other high-abundance toxins}

The SVMPs, CTLs, SVSPs, and PLA2s account for $74 \%$ of the reads mapping to toxin sequences (Figure 3), $73 \%$ of the toxin clusters, and $82 \%$ of the unique toxin sequences. The remaining toxins belong to 16 different classes. Many of these are low-abundance transcripts (Figure 2 and Table 3) and may not actually function as significant toxins, whereas several others have high to moderate abundances and represent significant components of the venom.

The most abundant toxin transcript and the most abundant transcript overall (Figure 2) was a small basic myotoxin related to crotamine $[53,54]$. The precursor protein is just 70 amino acids in length with a predicted 22amino-acid signal peptide. This transcript was detected by Rokyta et al. [11], but the coding sequence was prematurely truncated in their sequence because of a single nt deletion. This toxin accounts for $16.8 \%$ of the toxin reads (Figure $3 \mathrm{~A}$ ) and $5.9 \%$ of the total reads. Crotamine, originally isolated from the venom of $C$. durissus, causes spastic paralysis in mice and is found in the venoms of many species of Crotalus [54]. Muscle spasms, twitching, and paralysis of the legs have been reported for human envenomations by C. adamanteus [20]. Interestingly, Straight et al. [55] noted that individuals of $C$. adamanteus from populations in southern and central Florida lack this toxin in their venoms. Given that this myotoxin is the most abundant transcript in the venom of our specimen, its absence in southern populations points to a dramatic difference in venoms within this species and the potential for significantly different pathological effects associated with bites from different $C$. adamanteus populations.

A single L-amino-acid oxidase (LAAO) transcript was the second most abundant toxin transcript (Figure 2B), consistent with the previously detected LAAO activity in the C. adamanteus venom [46]. This single transcript accounted for $5.3 \%$ of the reads mapping to toxins and $1.9 \%$ of the total reads. LAAOs are flavoproteins, giving the venom its yellow color; can be edema- or apoptosis-inducing; and can induce or inhibit platelet aggregation [56]. These effects are probably mediated by $\mathrm{H}_{2} \mathrm{O}_{2}$ released during the oxidation reaction catalyzed by the enzyme. The 29th most abundant toxin transcript was a cysteine-rich secretory protein (CRISP) (Figure 2B and Table 3), accounting for $1.3 \%$ of the toxin reads (Figure 3A). Although CRISPs are widely found in snake venoms, their precise effects are not well established [57], but they appear to interfere with smooth-muscle contraction [58,59]. A single transcript for a bradykininpotentiating and C-type natriuretic peptide transcript (BPP) was found to account for $0.7 \%$ of the toxin reads (Figure 3A). The encoded protein is similar to a protein identified in Sistrurus catenatus (GenBank accession: DQ464265) that was hypothesized to reduce blood pressure in envenomated prey [25]. A loss of blood pressure has been reported in human envenomations by C. adamanteus [20].

\section{Other low-abundance toxins}

The remaining 17 clusters are classified as "others" in Figure 3A. Because each has a relatively low expression level (Table 3), many of these should be considered putative toxins until their presence in the $C$. adamanteus venom is confirmed proteomically and pharmacological effects are associated with them.

Rokyta et al. [11] detected the presence of a transcript encoding a protein homologous to ohanin from Ophiophagus hannah $[60,61]$ and to a homologous protein from Lachesis muta [62]; we found a transcript identical to that of Rokyta et al. [11]. Pung et al. [60,61] found the $O$. hannah version of this protein to increase pain sensitivity (hyperalgesia) and to induce temporary hypolocomotion in mice and proposed naming the class vespryns (VESP). Exceptionally intense pain has been reported after envenomation of humans by C. adamanteus [20], although whether such pain is due to a specific toxin is not clear.

We detected three different nucleotidases (NUCs) and five different phosphodiesterases (PDEs) in the venomgland transcriptome of $C$. adamanteus. Only one of the NUCs and three of the PDEs had signal peptides, and 
we therefore only considered these as potential toxins: NUC, PDE, PDE-4, and PDE-6 (Table 3). The roles of these enzymes in venoms are uncertain, but their primary function may be to liberate toxic nucleosides [63-65]. Significant PDE activity has been detected previously in the venom of $C$. adamanteus [46].

The $C$. adamanteus venom-gland transcriptome contained three Kunitz-type protease inhibitors (KUNs). Two of these shared more than $75 \%$ animo-acid identity with a KUN from Austrelaps labialis (GenBank accession: B2BS84), an Australian elapid. All three KUNs have domains that place them in the superfamily of bovine pancreatic trypsin-like inhibitors, and snake toxins from this family are known to inhibit plasma serine proteinases. Although KUNs are commonly observed in snake venoms, their role in envenomation (if any) is not well defined [66]. The three KUNs detected for $C$. adamanteus are all at relatively low abundances, suggesting that they are not major components of the venom.

We identified two transcripts, HYAL-1 and HYAL-2, encoding hyaluronidase-like proteins. Hyaluronidases are generally regarded as venom components that promote the dissemination of other venom components by degrading the extracellular matrix at the site of injection [67], although they may have more direct toxic effects [68]. The coding sequences of our two transcripts differ only in the presence of a 765-nt deletion in HYAL-2 relative to HYAL-1. Truncated hyaluronidases such as HYAL-2 have been detected in the venoms of other viperid species [67] and may represent an example of alternative splicing. We also identified a transcript encoding a glutaminyl-peptide cyclotransferase (glutaminyl cyclase; GC). Many snake venom components have $\mathrm{N}$ termini blocked by pyroglutamate, and GCs catalyze the formation of this block. This component is related more to maturation and protection of other toxins and probably contributes only indirectly to toxicity [69].

We identified six growth-factor-related sequences in the venom-gland transcriptome of $C$. adamanteus: a nerve growth factor (NGF), a neurotrophic factor (NF), two vascular endothelial growth factors (VEGF) in a single cluster, and a cysteine-rich with EGF-like domain protein (CREGF). The NGF transcript encodes a 241 amino-acid precursor protein and shares $99 \%$ aminoacid identity with a NGF from C. durissus (GenBank accession: AAG30924). The NF transcript encodes a 180amino-acid precursor that shares homology with mesencephalic astrocyte-derived neurotrophic factors. We found no close venom-related sequences for this NF in the available databases. The VEGF sequences appear to be alternatively spliced versions of one another. VEGF1a encodes a 192-amino-acid precursor, and VEGF-1b encodes a 148-amino-acid precursor. Aside from the 132-nt deletion in VEGF-1b relative to VEGF-1a, their coding sequences are identical. Both forms have database matches of the same length with $99 \%$ amino-acid identity from Trimeresurus flavoviridis (GenBank accessions: AB154418 and AB154419). Finally, we detected the same cysteine-rich with EGF-like domain protein as described by Rokyta et al. [11].

The final two putative toxin transcripts are of questionable significance because of their low expression levels. A single sequence with $77 \%$ amino-acid identity to a waprin (WAP) sequence from Philodryas olfersii (GenBank accession: EU029742), a rear-fanged colubrid, was detected. Related sequences have been detected in a variety of other rear-fanged snake species, but such proteins are only known to exhibit antimicrobial activity [70]. We detected a venom factor (VF) transcript that shares $87 \%$ animo-acid identity with a VF from Austrelaps superbus (GenBank accession: AY903291) [71]. The C. adamanteus VF transcript encodes a 1,652-amino-acid precursor with a 22-amino-acid signal peptide. The best-studied member of this toxin family is cobra venom factor, which is known to activate the complement system [72]. The extremely low expression levels of these transcripts may indicate that they represent the orthologous genes to the ancestors of the known toxic forms and may therefore have no toxic functions.

\section{Comparison to previous work}

Rokyta et al. [11] previously described toxin transcripts in the venom-gland transcriptome of $C$. adamanteus on the basis of 454 pyrosequencing. Their work used RNA from the venom gland of the same individual used in the present work. They found 40 unique toxin transcripts, 10 of which contained only partial coding sequences. Table 4 lists the closest matches from our current sequences to those of Rokyta et al. [11]. The vast majority of the 454-based sequences had either identical matches in our current set of toxins or matches with less than $1 \%$ nt divergence (Table 4). Only a single 454 toxin, SVSP-9, did not have a close match. This sequence contains only a partial coding sequence and therefore may not represent a true, functional toxin.

\section{Nontoxin transcripts}

We characterized the nontoxin genes expressed in the C. adamanteus venom gland by two means. First, we took all of the contigs from one of our four de novo NGen assemblies based on 20 million merged reads and conducted a full Blast2Go [73] analysis on the contigs comprising $\geq 100$ reads. Of the 12,746 contigs (assembly 2 in Table 2), we were able to provide gene ontology (GO) annotations for 9,040 of them (Figure 4A). The major functional classes (level 2) represented in these results were binding and catalysis, followed by transcription regulation (Figure 4B). The major biological process 
Table 4 Correspondence with the results of Rokyta et al. [11]

\begin{tabular}{|c|c|c|c|c|}
\hline 454 name & Accession & Closest match & $\%$ nt divergence & Notes \\
\hline CREGF & HQ414087 & CREGF & 0.1 & \\
\hline CRISP & HQ414088 & CRISP & 0.0 & Identical \\
\hline CTL-1 & HQ414089 & CTL-4a & 0.0 & Identical \\
\hline CTL-2 & HQ414090 & CTL-8a & 0.0 & Identical \\
\hline CTL-3 & HQ414091 & CTL-1 & 0.0 & Identical \\
\hline CTL-4 & HQ414092 & CTL-9a & 0.8 & \\
\hline CTL-5 & HQ414093 & CTL-3e & 0.9 & \\
\hline CTL-6 & HQ414094 & $C T L-12 b$ & 0.0 & Identical \\
\hline CTL-7 & HQ414095 & CTL-10 & 0.0 & Identical \\
\hline CTL-8 & HQ414096 & CTL-2a & 0.0 & Identical \\
\hline CTL-9 & HQ414097 & CTL-5a & 0.0 & Identical \\
\hline HYAL & HQ414098 & HYAL-1 & 0.0 & 454 version incomplete \\
\hline LAAO & HQ414099 & LAAO & 0.0 & Identical \\
\hline MYO & $\mathrm{HQ} 414100$ & MYO & 0.0 & 454 version has 1-nt deletion that truncates the coding sequence prematurely \\
\hline NUC & HQ414101 & NUC & 0.0 & 454 version incomplete \\
\hline PDE-1 & HQ414102 & PDE & 0.0 & 454 version has 123 -nt insertion \\
\hline PDE-2 & HQ414103 & PDE-2 (nontoxin) & 0.0 & 454 version incomplete; no signal peptide; no longer considered toxin \\
\hline PLA2 & HQ414104 & PLA2-1b & 0.0 & Identical \\
\hline PLB & HQ414105 & PLB (nontoxin) & 0.2 & No longer considered toxin \\
\hline SVMP-1 & HQ414106 & SVMPII-3b & 0.0 & Identical \\
\hline SVMP-2 & HQ414107 & SVMPII-3b/c & 0.5 & \\
\hline SVMP-3 & HQ414108 & SVMPII-5a & 0.3 & \\
\hline SVMP-4 & HQ414109 & SVMPIII-2d & 1.2 & \\
\hline SVMP-5 & HQ414110 & SVMPIII-4b & 1.0 & \\
\hline SVMP-6 & HQ414111 & SVMPIII-2d & 0.2 & \\
\hline SVMP-7 & $\mathrm{HQ} 414112$ & SVMPIII-4a & 0.0 & Identical \\
\hline SVMP-8 & HQ414113 & SVMPIII-5 & 0.5 & 454 version incomplete \\
\hline SVMP-9 & $\mathrm{HQ} 414114$ & SVMPIII-1a/b & 0.0 & 454 version incomplete \\
\hline SVMP-10 & HQ414115 & SVMPIII-6 & 0.0 & 454 version incomplete \\
\hline SVMP-11 & HQ414116 & SVMPIII-3a & 0.0 & 454 version incomplete \\
\hline SVSP-1 & HQ414117 & SVSP-3a & 0.0 & 454 version has 1-nt deletion that truncates the coding sequence prematurely \\
\hline SVSP-2 & HQ414118 & SVSP-1 & 0.0 & Identical \\
\hline SVSP-3 & HQ414119 & SVSP-7a & 0.0 & Identical \\
\hline SVSP-4 & HQ414120 & SVSP-5 & 0.1 & \\
\hline SVSP-5 & HQ414121 & SVSP-9 & 0.5 & \\
\hline SVSP-6 & HQ414122 & SVSP-6 & 0.0 & Identical \\
\hline SVSP-7 & HQ414123 & SVSP-4b & 0.0 & 454 version incomplete \\
\hline SVSP-8 & HQ414124 & SVSP-2 & 0.0 & 454 version incomplete \\
\hline SVSP-9 & HQ414125 & None & $>10$ & 454 version incomplete \\
\hline VESP & HQ414126 & VESP & 0.0 & Identical \\
\hline
\end{tabular}



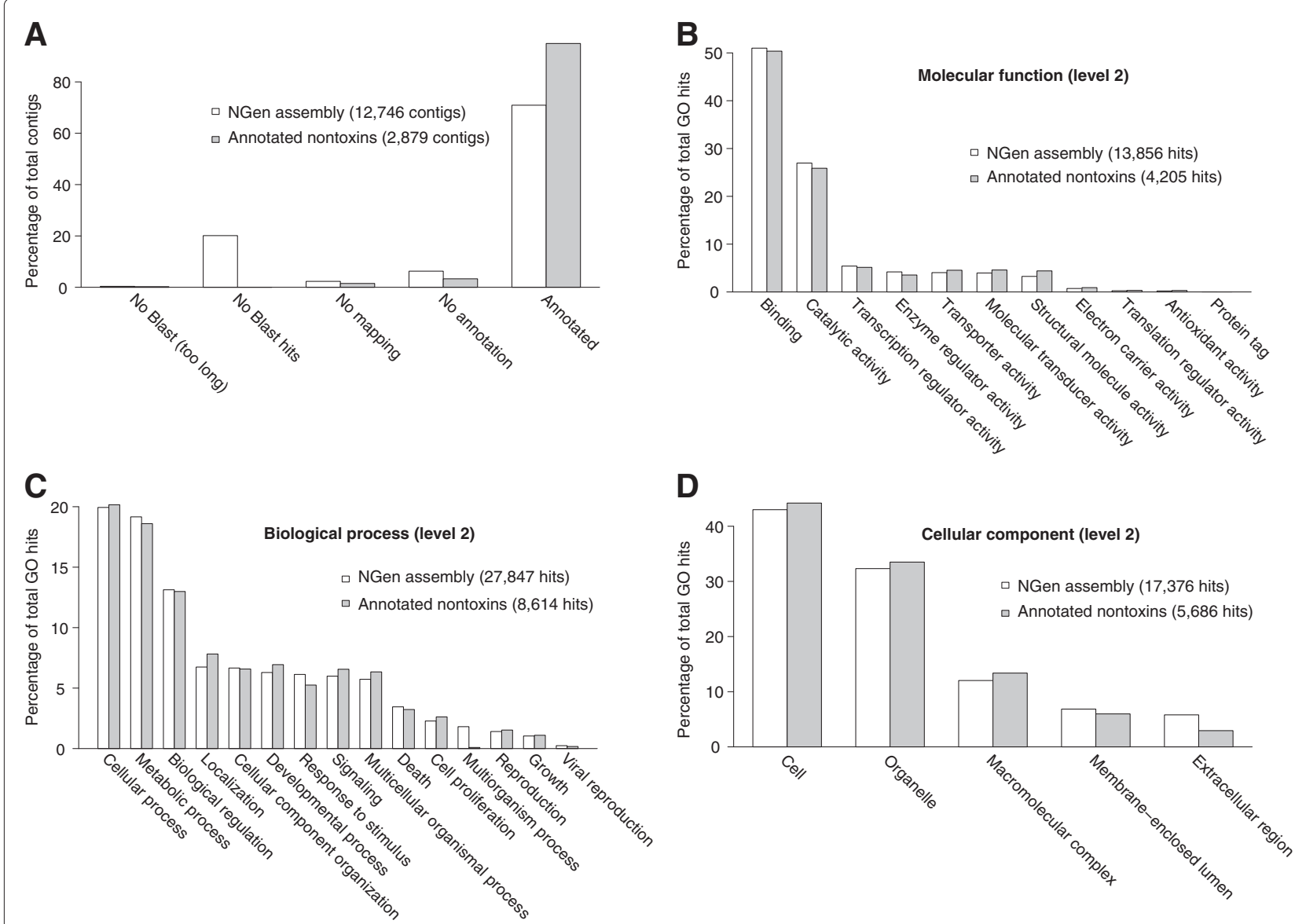

Figure 4 Comparison of gene ontology $(\mathrm{GO})$ results for our annotated full-length nontoxin sequences with those of the contigs from a de novo assembly with NGen. Only level $2 \mathrm{GO}$ terms are shown. The distributions of GO terms are similar across data sets, suggesting that the annotated transcripts provided a comprehensive characterization of the genes expressed in the venom gland. (A) The distributions of sequences reaching various stages of identification and annotation are shown. The level $2 \mathrm{GO}$ terms are shown for molecular function (B), biological process (C), and cellular component (D).

GO terms (level 2) were cellular processes and metabolic processes (Figure 4C). Interestingly, viral reproductive function was detected and probably represents the activity of transposable elements or retroviruses like those previously noted in snake venom-gland transcriptomes [34]. The major cellular component GO terms (level 2) were cell and organelle (Figure 4D). For these results, we made no attempt to exclude toxin sequences, because they are necessarily a small minority of the total sequences, and did not require that contigs contain full-length coding sequences.

For our second approach, we used only the 2,879 transcripts with full-length coding sequences for nontoxin proteins. We analyzed these sequences with Blast2GO. The distributions of level 2 GO terms for these data were almost identical to those of the full NGen assembly described above (Figure 4), suggesting that our 2,879 annotated nontoxin sequences provide a representative sample of the full venom-gland transcriptome. The full distributions of GO terms for these sequences across all levels are shown in Figures 5, 6, and 7. As expected for a secretory tissue, processes related to protein production and secretion were well represented (e.g., protein transport and protein modification; Figure 5), as were protein-binding functions (Figure 6) and proteins localized to the endoplasmic reticulum (ER) and the Golgi apparatus (Figure 7).

Four of the top 20 most highly expressed nontoxin genes (Table 5), including the most highly expressed, were protein disulfide isomerases (PDIs). In particular, they were members of the PDI family that is retained in the ER and are characterized by having two or more PDI domains, which are similar to thioredoxin. PDIs catalyze the formation or breaking of disulfide bonds and are therefore involved in protein folding. Molecular chaperones were well represented in the top 20 nontoxins by four genes: endoplasmin (a member of the HSP90 family), calreticulin, 78-kDA glucose-regulated protein (GRP78), 


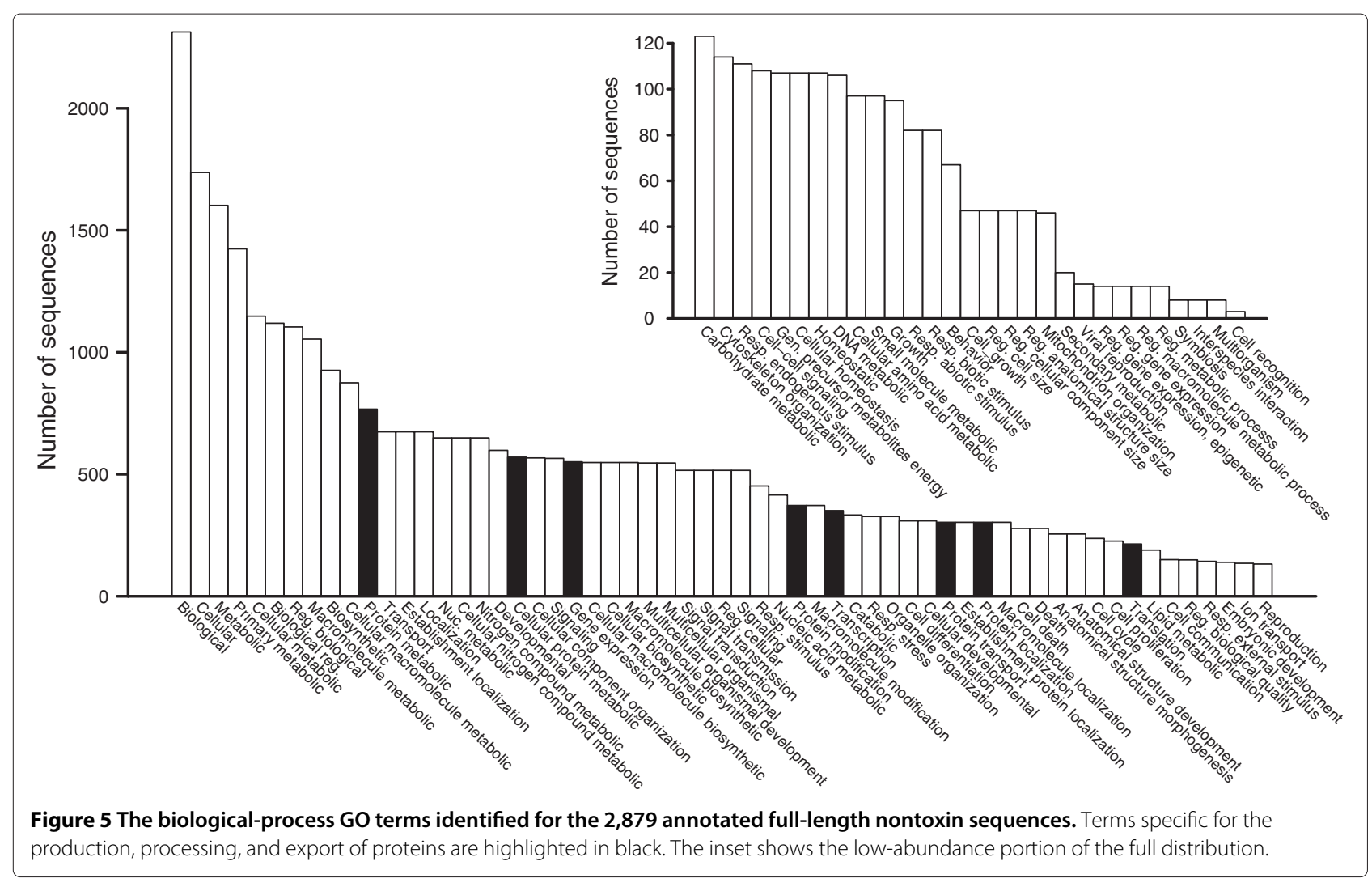

and heat shock protein 5 . The latter gene appears to be a splice variant of GRP78, differing within the coding region by two point mutations and two short deletions. All of these chaperones are ER specific. Six of the top 20 nontoxins were mitochondrial genes involved in oxidative cellular respiration, consistent with the high energetic demands of venom production [74]: cytochrome C oxidase subunits I and III, cytochrome B, and NADH dehydrogenase subunits 1,4 , and 5 . The cells of venom glands are particularly rich in mitochondria [75]. Four genes were involved in various aspects of translation: two translation elongation factors, $18 \mathrm{~S}$ rRNA, and vigilin. Vigilins are hypothesized to be involved in regulating mRNA stability and translation and might be involved in RNA-mediated gene silencing [76,77]. The final top 20 nontoxin gene was actin, a component of the cytoskeleton.

The abundances of several major classes of nontoxins are provided in Figure 3B. We identified 57 sequences with functions related to protein folding [19,78-80], including various classes of heat-shock proteins, protein-disulfide isomerases, peptidyl-prolyl cis-trans isomerases, dnaJcomplex components, and T-complex components. These sequences together accounted for $28.4 \%$ of the total reads mapping to nontoxins. Ribosomal-protein transcripts (cytoplasmic and mitochondrial) accounted for
9.5\% of the nontoxin reads, and mitochondrial genes accounted for another 9.0\%. Finally, we identified 110 sequences transcripts encoding proteins involved in protein degradation $[81,82]$, including proteins involved in the ubiquitin-proteasome system and the ER-associated protein-degradation system [83], which accounted for $2.6 \%$ of the nontoxin reads. Protein-quality control should be essential in a high-throughput protein-producing tissue such as a snake venom gland.

Our collection of nontoxins included several notable potential inhibitors of the toxins or other proteases (Table 6). Such inhibitors may play a role in preventing autolysis [84] or may serve to protect venom components once inside a victim [85]. We detected three cystatin-like transcripts in the venom gland. Cystatins are cysteineprotease inhibitors and have been detected in numerous elapid venom glands and venoms [85]. We detected three unique metalloproteinase inhibitors and two serine proteinase inhibitors (serpins). Finally, we found four unique PLA2 inhibitors.

\section{Sequence accession numbers}

The original, unmerged sequencing reads were submitted to the National Center for Biotechnology Information (NCBI) Sequence Read Archive under accession number SRA050594. The annotated toxin and nontoxin sequences 


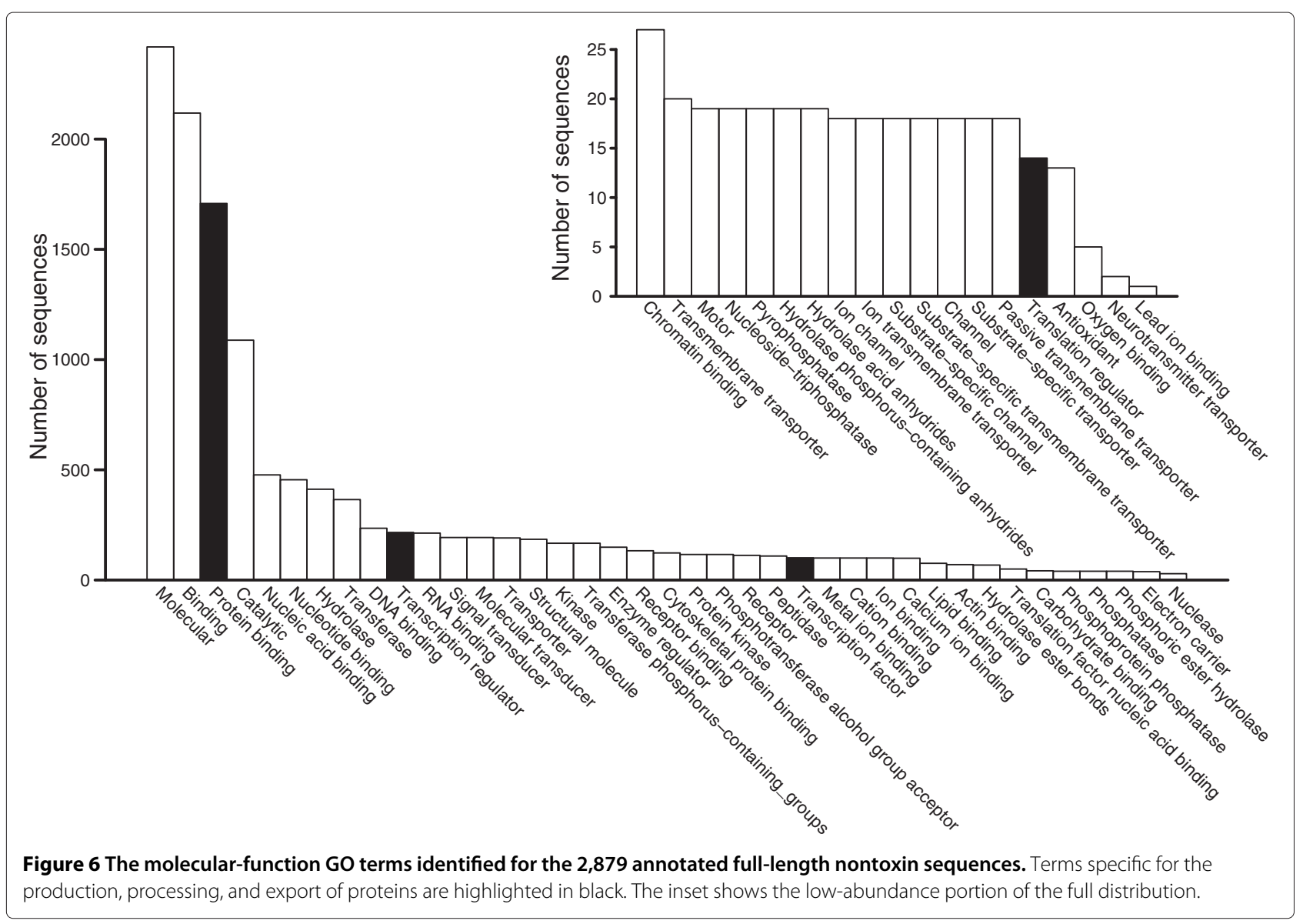

were submitted to the GenBank Transcriptome Shotgun Assembly (TSA) database under accession numbers JU173621-JU173743 (toxins) and JU173744-JU176622 (nontoxins).

\section{Conclusions}

We have described the most comprehensive venom-gland transcriptomic characterization of a snake species to date and provided full-length coding sequences for 123 unique toxin proteins and 2,879 unique nontoxin proteins. We have demonstrated the use of Illumina sequencing technology for the sequencing and de novo assembly of a tissue-specific transcriptome for a nonmodel species, C. adamanteus, for which genome-scale resources were previously unavailable. Because the nontoxin sequences in particular should be conserved across snake species, our results should greatly facilitate similar work with other venomous species, serving as an assembly template and reducing the number of reads for which de novo assembly will be necessary.

The expressed toxin genes in the venom gland of C. adamanteus provide a detailed portrait of a type I rattlesnake venom [46]. The most abundant transcript expressed in the $C$. adamanteus venom gland encoded a myotoxin homologous to crotamine. Crotamine is known to induce spastic paralysis [54], a symptom that has been observed in human envenomations by C. adamanteus [20]. Like those of most viperids, the bites of $C$. adamanteus result in significant tissue damage and necrosis, and we found that SVMPs, the major class of hemorrhagic toxins, dominated venom-gland gene expression. The second most abundant toxin transcript overall was an LAAO, which are also noted for causing local tissue damage [46]. Coagulopathy is a common occurrence with pit-viper bites [5]. The CTLs and SVSPs were also both diverse and abundant in the venom-gland transcriptome of $C$. adamanteus, and both classes primarily attack the hemostatic system. In terms of gene sequences of venom components, the venom of C. adamanteus is now the best-characterized snake venom, although a thorough proteomic analysis of the venom is still needed. The sequences we have generated will greatly facilitate such a proteomic characterization by serving as a database against which to query mass-spectrum results.

The expression patterns of the nontoxin genes in the venom gland of $C$. adamanteus reflect the proteinsecretory function of the tissue and the high energetic 


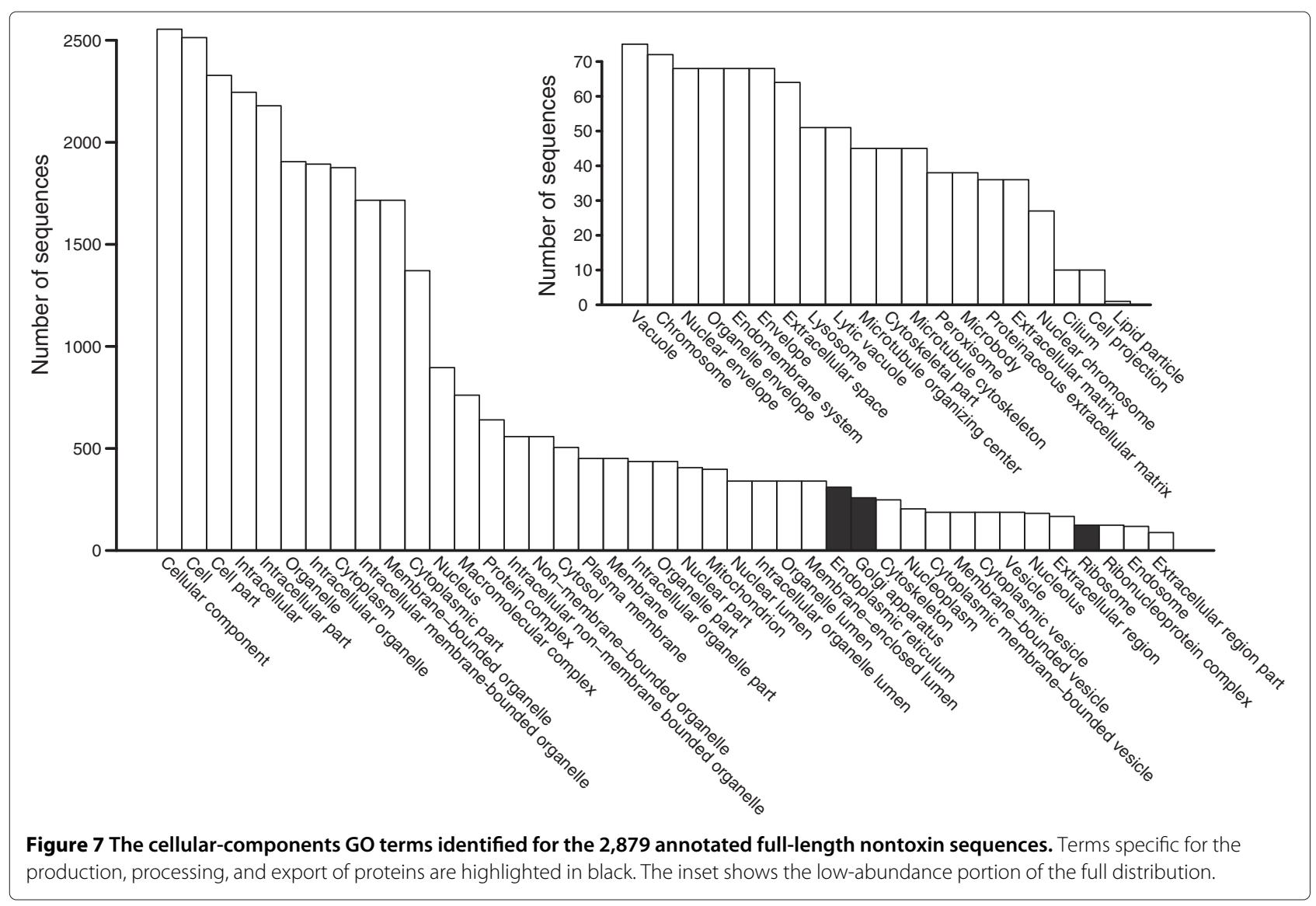

demands of rapid venom production [75]. The most highly expressed nontoxin genes were those involved in the production and processing of proteins and energy production to support these activities. Molecular chaperones and PDIs were particularly abundant. Though the expression patterns for nontoxins were not surprising, future comparisons with other snake species, especially those from other snake families, may be able to elucidate the origin and early stages of the evolution of the venom gland.

\section{Methods}

\section{Venom-gland transcriptome sequencing}

We sequenced the venom-gland transcriptome of a single animal from Florida (Wakulla County): an adult female weighing $393 \mathrm{~g}$ with a snout-to-vent length of $792 \mathrm{~mm}$ and a total length of $844 \mathrm{~mm}$. To stimulate transcription in the venom glands, we anesthetized the snake by propofol injection $(10 \mathrm{mg} / \mathrm{kg})$ and extracted venom by electrostimulation under anesthesia [86]. After venom extraction, the animal was allowed to recover for four days while transcription levels reached their maxima [87]. The snake was euthanized by injection of sodium pentobarbitol (100 $\mathrm{mg} / \mathrm{kg}$ ), and its venom glands were subsequently removed. The above techniques were approved by the Florida State
University Institutional Animal Care and Use Committee (IACUC) under protocol \#0924.

Sequencing and nonnormalized cDNA library preparation were performed by the HudsonAlpha Institute for Biotechnology Genomic Services Laboratory (http:// www.hudsonalpha.org/gsl/). Transcriptome sequencing was performed essentially as described by Mortazavi et al. [88] in a modification of the standard Illumina methods described in detail in Bentley et al. [89]. Total RNA was reduced to poly-A+ RNA with oligo$\mathrm{dT}$ beads. Two rounds of poly-A+ selection were performed. The purified mRNA was then subjected to a mild heat fragmentation followed by random priming for first-strand synthesis. Standard second-strand synthesis was followed by standard library preparation with the double-stranded cDNA as input material. This approach is similar to that of Illumina's TruSeq RNAseq library preparation kit. Sequencing was performed in one lane on the Illumina HiSeq 2000 with 100-base-pair paired-end reads.

\section{Transcriptome assembly and analysis}

The average insert length of our cDNA library was $\sim 170$ nt, excluding the Illumina adaptors. With 100-base-pair 
Table $\mathbf{5}$ The $\mathbf{2 0}$ most highly expressed nontoxin transcripts

\begin{tabular}{|c|c|c|c|c|}
\hline Name & Length & $\%$ reads & Function & Accession \\
\hline Protein disulfide isomerase & 2970 & 5.223 & Rearrange disulfide bonds (ER) & JU175360 \\
\hline Cytochrome C oxidase subunit I & 2789 & 0.966 & Electron transport chain & JU175042 \\
\hline Cytochrome B & 1275 & 0.499 & Electron transport chain & JU175040 \\
\hline Translation elongation factor $1 \alpha 1$ & 1985 & 0.459 & Translation & JU174424 \\
\hline 18S rRNA & 2509 & 0.421 & Ribosomal component & JU173759 \\
\hline Calreticulin & 1661 & 0.406 & Protein chaperone (ER) & JU174061 \\
\hline Endoplasmin (HSP90 family) & 3012 & 0.333 & Protein chaperone (ER) & JU174456 \\
\hline 78 kDa glucose-regulated protein & 2676 & 0.332 & Protein chaperone (ER) & JU174713 \\
\hline Heat shock protein 5 (GRP78 splice variant?) & 2063 & 0.327 & Protein chaperone (ER) & JU174801 \\
\hline NADH dehydrogenase subunit 5 & 4448 & 0.272 & Electron transport chain & JU175113 \\
\hline Cytochrome C oxidase subunit III & 2103 & 0.239 & Electron transport chain & JU175043 \\
\hline Protein disulfide isomerase A6 & 4933 & 0.212 & Rearrange disulfide bonds (ER) & JU175358 \\
\hline Nucleobindin 2 & 2937 & 0.203 & Calcium binding & JU175278 \\
\hline Protein disulfide isomerase A3 & 1904 & 0.186 & Rearrange disulfide bonds (ER) & JU175355 \\
\hline NADH dehydrogenase subunit 1 & 1878 & 0.173 & Electron transport chain & JU175111 \\
\hline NADH dehydrogenase subunit 4 & 1751 & 0.172 & Electron transport chain & JU175112 \\
\hline Protein disulfide isomerase A4 & 2540 & 0.159 & Rearrange disulfide bonds (ER) & JU175356 \\
\hline Translation elongation factor 2 & 3057 & 0.147 & Translation & JU174429 \\
\hline Vigilin 2 & 6107 & 0.129 & mRNA stability and translation & JU176512 \\
\hline Actin, cytoplasmic 2 & 1971 & 0.124 & Cytoskeleton & JU173777 \\
\hline
\end{tabular}

paired-end sequencing, the majority of paired-end reads overlapped at their 3' ends. Because read quality declines toward the 3' ends of reads, we developed a method similar to that of Rodrigue et al. [36] for merging the overlapping pairs into single, long, high-quality reads. The members of each pair of reads were slid along each other, and, for each overlap of length $n$, we calculated the probability of getting the observed number of matches $k$ by chance using a binomial probability given by

$$
P(k \mid n)=\left(\begin{array}{l}
n \\
k
\end{array}\right)\left(\frac{1}{4}\right)^{k}\left(\frac{3}{4}\right)^{n-k}
$$

assuming any of the four nucleotides is equally likely to be at any position. To be conservative, we only merged reads

Table 6 Toxin and protease inhibitors detected in the venom-gland transcripts

\begin{tabular}{|c|c|c|c|c|}
\hline Name & Length & $\%$ reads & Function & Accession \\
\hline Cystatin 1 & 790 & $9.80 \times 10^{-4}$ & Cysteine-protease inhibitor & JU174278 \\
\hline Cystatin B & 460 & $1.23 \times 10^{-3}$ & Cysteine-protease inhibitor & JU174279 \\
\hline Cystatin 2 & 709 & $1.31 \times 10^{-3}$ & Cysteine-protease inhibitor & JU174280 \\
\hline Metalloproteinase inhibitor 1 & 820 & $1.04 \times 10^{-3}$ & Metalloproteinase inhibitor & JU175124 \\
\hline Metalloproteinase inhibitor 2 & 2560 & $2.57 \times 10^{-3}$ & Metalloproteinase inhibitor & JU175125 \\
\hline Metalloproteinase inhibitor 3 & 2202 & $1.01 \times 10^{-3}$ & Metalloproteinase inhibitor & $J U 175126$ \\
\hline PLA2 inhibitor beta & 1210 & $1.54 \times 10^{-3}$ & PLA2 inhibitor & $J U 175425$ \\
\hline PLA2 inhibitor gamma B 1 & 1492 & $3.68 \times 10^{-3}$ & PLA2 inhibitor & JU175444 \\
\hline PLA2 inhibitor gamma B 2 & 1694 & $7.70 \times 10^{-4}$ & PLA2 inhibitor & JU175442 \\
\hline PLA2 inhibitor B & 2339 & $1.07 \times 10^{-3}$ & PLA2 inhibitor & JU175443 \\
\hline Serpin B6 & 1708 & $9.68 \times 10^{-3}$ & Serine-proteinase inhibitor & JU175869 \\
\hline Serpin H1 & 2004 & $9.40 \times 10^{-4}$ & Serine-proteinase inhibitor & JU175870 \\
\hline
\end{tabular}


if the minimum probability was less than $10^{-10}$ and the second smallest probability was at least 1000 times larger (Figure 1A). The latter condition was meant to help avoid merging reads that span highly repetitive regions. For cases in which the insert size was less than the read length, sequence data outside the overlap were assumed to represent adaptors and were deleted. We updated quality scores for the overlapping positions following the approach of Rodrigue et al. [36]. For merged reads, quality scores for nonoverlapping bases were left unchanged (Figure 1B). The unmerged reads were typically those pairs from the longer end of the insert-size distribution.

Because of the inherent difficulty in de novo transcriptome assembly, we used a diverse array of assembly approaches and combined the results for a final data set. We performed assemblies using ABySS version 1.2.6 $[37,38]$ under a wide array of parameter values using both the merged and unmerged reads. In particular, we used $k$-mer values of $51,61,71,81$, and 91 and varied the coverage $(c)$ and erode $(e)$ parameters from 2 to 1,000 . We set $E=0, m=20$, and $s=200$ for all assemblies. Trans-ABySS [90] provided little or no improvement of our assemblies, primarily because assembly quality appeared to be more dependent on the coverage and erode parameters than on the $k$-mer length. We also conducted assemblies using both the merged and unmerged reads with Velvet version 1.1.02 [39] and $k$-mer values of 71,81 , and 91 . We selected the best of these assemblies on the basis of the N50 values for further assembly into transcripts with Oases version 0.1.20 (http://www.ebi. ac.uk/ zerbino/oases/) [40]. For Oases, we set the minimum transcript length to $300 \mathrm{nt}$ and the coverage cutoff to 10. We also followed the approach of Rokyta et al. [11] and used the NGen2.2 assembler from DNAStar (http://www.dnastar.com/). Because this assembler is limited to 20-30 million reads, we used only the merged reads. We performed four independent assemblies: three with 20 million merged reads each and one with the remaining 12,114,709 merged reads. Each assembly was performed with the default settings for high-stringency, de novo transcriptome assembly for long Illumina reads, including default quality trimming. The high-stringency setting corresponded to setting the minimum match percentage to $90 \%$. We retained contigs comprising at least 100 reads.

In addition to the all-at-once assembly approaches above, we developed an iterative approach that was both more effective at generating full-length transcripts and more computationally efficient. The first step consisted of applying our Extender program (see below) as a de novo assembler starting from 1,000 reads. Full-length transcripts were identified with blastx searches (see below), then used as templates in a reference-based assembly in NGen3.1 with a $98 \%$ minimum match percentage to filter reads corresponding to identified transcripts. Ten million of the unassembled sequences were then used in a de novo transcriptome assembly in NGen3.1 with the same settings as described above for de novo assembly except that the minimum match percentage was increased to $93 \%$ and contigs comprising less than 200 sequences were discarded. The resulting sequences were identified, where possible, by means of blastx searches, and the identified full-length transcripts were used in another templated assembly to generate a further-reduced set of reads. This iterative process was repeated two additional times.

To provide transcriptional profiles of the venom gland, we performed GO annotation with Blast2GO [73]. We ran full analyses on one of NGen assemblies of 20 million merged reads, including blastx searches, GO mapping, and annotation. We used the default Blast2GO parameters throughout. We converted the GO annotation to generic GO-slim terms. We ran the same analysis on the combined set of annotated nontoxin sequences.

For gene identification and annotation, we conducted blastx searches using mpiblast version 1.6.0 (http://www. mpiblast.org/) of the consensus sequences of contigs of our assemblies against the NCBI nonredundant protein database (nr; downloaded March 2011 and updated through November 2011). We used an E-value cut-off of $10^{-4}$, and only the top 10 matches were considered. For toxin identification, hit descriptions were searched for a set of keywords based on known snake-venom toxins and protein classes. Any sequence matching these keywords was checked for a full-length coding sequence. We generally only retained transcripts with full-length coding sequences (but see below). For the iterative assembly approach, the remaining, presumably nontoxin-encoding, contigs were screened for those whose match lengths were at least $90 \%$ of the length of at least one of their database matches. This step was intended to minimize the number of fragmented or partial sequences that were considered for annotation. In addition, we sorted the contigs of the three 20-million-sequence NGen assemblies from the all-at-once approach on the basis of the number of reads and attempted to annotate the top 500 contigs from one assembly and the top 100 from the other two.

We estimated transcript abundances using highstringency reference-based assemblies in NGen3.1 with a minimum match percentage of 95 . Ten million of the merged reads were mapped onto the full-length, annotated transcripts, and the percentage of reads mapping to each transcript was used as a proxy for abundance.

\section{The extender}

The purpose of Extender is to estimate quickly one or more full-length transcript sequences from a large 
number of high-quality sequence reads. The procedure begins with one or more seed sequences provided by the user. The seeds can be known sequences (e.g., partial transcripts from a previous assembly) or simply sequences of one or more of the reads. The Extender procedure begins by hashing the $k$-mers observed at the two ends of the seeds. If $k$ is set to 50 , for example, then the 50base sequence present at the 5 ' end of each seed is used as a key in a hash table, and the hash value is a pointer to the seed in the list of seeds. A second hash table is likewise used for $k$-mers from the 3' ends of the seeds. Note that this method requires that all initial $k$-mers be unique (that no two sequence ends be identical). Once the seeds are hashed, the seeds are extended with the set of reads provided by the user as follows. The two $k$ mers from the ends of each read are looked up in each hash table. If the key is present in the hash table, the seed is extended by concatenation of the nonoverlapping bases from the read onto the appropriate end of the seed. If the key is absent, the reverse complement of the read is used to extend the seed if the end $k$-mers are found. After each extension, the $k$-mer key facilitating the extension is removed from the hash table and the new $k$-mer key is added (the reference to the seed remains the same). The procedure is repeated until the reads have been cycled through $N$ times, where $N$ is chosen by the user. Cycling is beneficial because the Extender does not reset to the beginning of the read list when an extension is made.

Extension of a seed typically terminates when the end of the full-length transcript is reached or when a sequencing error is encountered in the end of an incorporated read. The presence of low-frequency biological artifacts (e.g., unspliced introns) may also result in termination of the extension. In order to improve the accuracy of the consensus sequence prediction, Extender can create replicate seeds for a particular seed by sequentially trimming one base at a time from both ends. Using replicate seeds allows several independent sequences that represent the same target consensus sequence to be generated simultaneously, and these replicates are entirely independent because they begin with different keys. The user can obtain the final estimate of the sequence corresponding to each original seed by taking the consensus across replicates or by simply choosing the replicate producing the longest sequence. We took the former approach for all of our assembly efforts. Overall, Extender is highly inefficient with its use of data and requires many long, high-quality reads, but it is extremely computationally efficient, having short run times and low memory requirements.

We used Extender in two different ways: to complete partial toxin transcripts and as a de novo assembler. For the former, we used partial toxin transcripts from NGen assemblies that were found to have fragments of coding sequence homologous with known toxins. The partial transcripts were trimmed to just the partial coding sequence and used as seeds. To use Extender as a de novo assembler, we seeded it with 1,000 random reads. For both applications, we used a $k$-mer size of 100,20 replicates, 10 cycles through the complete set of merged reads excluding all reads with any bases with quality scores less than 30 .

\section{Abbreviations}

BPP: Bradykinin potentiating and C-type natriuretic peptides; CTL: C-type lectin; CREGF: Cysteine-rich with EGF-like domain; CRISP: Cysteine-rich secretory protein; Gb: Gigabase; GC: Glutaminyl-peptide cyclotransferase; GO: Gene ontology; HYAL: Hyaluronidase; KUN: Kunitz-type protease inhibitor; LAAO: L amino-acid oxidase; MYO: Myotoxin (crotamine); NGF: Nerve growth factor; NF: Neurotrophic factor; nt: Nucleotide; NUC: Nucleotidase; PDE: Phosphodiesterase; PDI: Protein disulfide isomerase; PLA2: Phospholipase $A_{2}$; SVMP: Snake venom metalloproteinase (types II and III); SVSP: Snake venom serine proteinase; VEGF: Vascular endothelial growth factor; VESP: Vespryn (ohanin-like); VF: Venom factor; WAP: Waprin.

\section{Competing interests}

The authors declare that they have no competing interests.

\section{Authors' contributions}

The project was conceived and planned by DR and AL. DR, MM, and KA collected and analyzed the data. DR wrote the manuscript. All authors read and approved the final manuscript.

\section{Acknowledgements}

The authors thank Kenneth P. Wray for dissecting the venom glands and Darryl Heard for training DRR in the electrostimulation technique for venom extraction. Computational resources were provided by the Florida State University High-Performance Computing cluster, and the authors thank James C. Wilgenbusch for assistance in the use of these resources. Funding for this work was provided to DRR and ARL by Florida State University.

\section{Author details}

1 Department of Biological Science, Florida State University, Tallahassee, FL 32306-4295, USA. ${ }^{2}$ Department of Scientific Computing, Florida State University, Tallahassee, FL 32306-4120, USA.

Received: 14 March 2012 Accepted: 2 July 2012

Published: 16 July 2012

\section{References}

1. Chippaux JP: Snake-bites: appraisal of the global situation. Bull WHO 1998, 76:515-524

2. O'Neil ME, Mack KA, Gilchrist J, Wozniak EJ: Snakebite injuries treated in United States emergency departments, 2001-2004. Wilderness Env Med 2007, 18:281-287.

3. Langley RL: Deaths from reptile bites in the United States, 1979-2004. Clin Toxicol 2009, 47:44-47.

4. Theakston RDG, Warrell DA, Griffiths E: Report of a WHO workshop on the standardization and control of antivenoms. Toxicon 2003, 41:541-557.

5. Smith J, Bush S: Envenomations by reptiles in the United States. In Handbook of Venoms and Toxins of Reptiles. Edited by Mackessy SP. Boca Raton, Florida: CRC Press; 2010:475-490.

6. Neves-Ferreira AGC, Valente RH, Perales J, Domont GB: Natural inhibitors: innate immunity to snake venoms. In Handbook of Venoms and Toxins of Reptiles. Edited by Mackessy SP. Boca Raton, Florida: CRC Press; 2010:259-284.

7. Rucavado A, Lomonte B: Neutralization of myonecrosis, hemorrhage, and edema induced by Bothrops apser snake venom by homologous and heterologous pre-existing antibodies in mice. Toxicon 1996, 34:567-577. 
8. Huang KF, Chow LP, Chiou SH: Isolation and characterization of a novel proteinase inhibitor from the snake serum of Taiwan habu (Trimeresurus mucrosquamatus). Biochem Biophys Res Commun 1999, 263:610-616.

9. Valente RH, Dragulev B, Perales J, Fox JW, Domont GB: BJ46a, a snake venom metalloproteinase inhibitor. Eur J Biochem 2001, 268:3042-3052

10. Serrano SMT, Shannon JD, Wang D, Camargo ACM, Fox JW: $\mathbf{A}$ multifaceted analysis of viperid snake venoms by two-dimensional gel electrophoresis: An approach to understanding venom proteomics. Proteomics 2005, 5:501-510.

11. Rokyta DR, Wray KP, Lemmon AR, Lemmon EM, Caudle SB: $\mathbf{A}$ high-throughput venom-gland transcriptome for the eastern diamondback rattlesnake (Crotalus adamanteus) and evidence for pervasive positive selection across toxin classes. Toxicon 2011, 57:657-671

12. Biardi JE, Chien DC, Coss RG: California ground squirrel (Spermophilus beecheyi) defenses against rattlesnake venom digestive and hemostatic toxins. J Chem Ecol 2005, 31:2501-2518.

13. Biardi JE, Nguyen KT, Lander S, Whitley M, Nambiar KP: A rapid and sensitive fluorometric method for the quantitative analysis of snake venom metalloproteases and their inhibitors. Toxicon 2011, 57:342-347.

14. Jansa SA, Voss RS: Adaptive evolution of the venom-targeted vWF protein in opossums that eat pitvipers. PLoS One 2011, 6:e20997.

15. Harvey AL, Bradley KN, Cochran SA, Rowan EG, Pratt JA, Quillfeldt JA Jerusalinsky DA: What can toxins tell us for drug discovery?. Toxicon 1998, 36:1635-1640.

16. Ménez A: Functional architectures of animal toxins: a clue to drug design? Toxicon 1998, 36:1557-1572.

17. Escoubas P, King GF: Venomics as a drug discovery platform. Expert Rev Proteomics 2009, 6:221-224.

18. Bohlen CJ, Chesler AT, Sharif-Naeini R, Medzihradszky KF, Zhou S, King D Sánchez EE, Burlingame AL, Basbaum Al, Julius D: A heteromeric Texas coral snake toxin targets acid-sensing ion channels to produce pain. Nature 2011, 479:410-414

19. Hartl FU, Bracher A, Hayer-Hartl M: Molecular chaperones in protein folding and proteostasis. Nature 2011, 475:324-332.

20. Klauber LM: Rattlesnakes: Their Habits, Life Histories, and Influence on Mankind. second edition. Berkeley, California: University of California Press; 1997.

21. Gold BS, Dart RC, Barish RA: Bites of venomous snakes. N Engl J Med 2002, 347:347-356

22. Conant R, Collins JT: A Fieldguide to Reptiles and Amphibians of Eastern and Central North America. third edition. New York, New York: Houghton Mifflin Harcourt; 1998.

23. Palmer WM, Braswell AL: Reptiles of North Carolina. Chapel Hill, North Carolina: University of North Carolina Press; 1995.

24. Dundee HA, Rossman DA: The Amphibians and Reptiles of Louisiana. Baton Rouge, Louisiana: Louisiana University Press; 1996.

25. Pahari S, Mackessy SP, Kini RM: The venom gland transcriptome of the desert massasauga rattlesnake (Sistrurus catenatus edwardsii): towards an understanding of venom composition among advanced snakes (superfamily Colubroidea). BMC Mol Biol 2007, 8:115.

26. Casewell NR, Harrison RA, Wüster W, Wagstaff SC: Comparative venom gland transcriptome surveys of the saw-scaled vipers (Viperidae: Echis) reveal substantial intra-family gene diversity and novel venom transcripts. BMC Genomics 2009, 10:564.

27. Leão LI, Ho PL, de L M Junqueira-de Azevedo I: Transcriptomic basis for an antiserum against Micrurus corallinus (coral snake) venom. BMC Genomics 2009, 10:112.

28. Jiang Y, Li Y, Lee W, Xu X, Zhang Y, Zhao R, Zhang Y, Wang W: Venom gland transcriptomes of two elapid snakes (Bungarus multicinctus and Naja atra) and evolution of toxin genes. BMC Genomics 2011, 12:1.

29. Morgenstern D, Rohde BH, King GF, Tal T, Sher D, Zlotkin E: The tale of a resting venom gland: transcriptome of a replete venom gland from the scorpion Hottentotta judaicus. Toxicon 2011, 57:695-703.

30. Whittington CM, Papenfuss AT, Locke DP, Mardis ER, Wilson RK, Abubucker S, Mitreva M, Wong ESW, Hsu AL, Kuchel PW, Belov K, Warren WC: Novel venom gene discovery in the platypus. Genome Biol 2010, 11:R95.
31. Gremski LH, Silveira RBD, Chaim OM, Probst CM, Ferrer VP, Nowatzki J, Weinschutz HC, Madeira HM, Gremski W, Nader HB, Senff-Ribeiro A, Veiga SS: A novel expression profile of the Loxosceles intermedia spider venomous gland revealed by transcriptome analysis. Mol BioSyst 2010, 6:2403-2416.

32. Ruiming Z, Yibao M, Yawen H, Zhiyong D, Yingliang W, Zhijian C, Wenxin $L$ : Comparative venom gland transcriptome analysis of the scorpion Lychas mucronatus reveals intraspecific toxic gene diversity and new venomous components. BMC Genomics 2010, 11:452.

33. Hu H, Bandyopadhyay PK, Olivera BM, Yandell M: Characterization of the Conus bullatus genome and its venon-duct transcriptome. $B M C$ Genomics 2011, 12:60.

34. Durban J, Juárez $P$, Angulo $Y$, Lomonte B, Flores-Diaz M, Alape-Girón A Sasa M, Sanz L, Gutiérrez JM, Dopazo J, Conesa A, Calvete JJ: Profiling the venom gland transcriptomes of Costa Rican snakes by 454 pyrosequencing. BMC Genomics 2011, 12:259.

35. Gilles A, Meglécz E, Pech M, Ferreira S, Malausa T, Martin JF: Accuracy and quality assessment of $454 \mathrm{GS}-\mathrm{FLX}$ Titanium pyrosequencing. $B M C$ Genomics 2011, 12:245.

36. Rodrigue S, Materna AC, Timberlake SC, Blackburn MC, Malmstrom RR, Aim EJ, Chisholm SW: Unlocking short read sequencing for metagenomics. PLoS One 2010, 5:e11840

37. Birol I, Jackman SD, Nielsen CB, Qian JQ, Varhol R, Stazyk G, Morin RD Zhao Y, Hirst M, Schein JE, Horsman DE, Connors JM, Gascoyne RD, Marra MA, Jones SJM: De novo transcriptome assembly with ABySS. Bioinformatics 2009, 25:2872-2877.

38. Simpson JT, Wong K, Jackman SD, Schein JE, Jones SJM, Birol I: ABySS: a parallel assembler for short read sequence data. Genome Res 2009, 19:1117-1123.

39. Zerbino DR, Birney E: Velvet: algorithms for de novo short read assembly using de Bruijn graphs. Genome Res 2008, 18:821-829.

40. Schulz MH, Zerbino DR, Vingron M, Birney E: Oases: robust de novo RNA-seq assembly across the dynamic range of expression levels. Bioinformatics 2012, 28:1086-1092.

41. Feldmeyer B, Wheat CW, Krezdorn N, Rotter B, Pfenninger M: Short read Illumina data for the de novo assembly of a non-model snail species transcriptome (Radix balthica, Basommatophora, Pulmonata), and a comparison of assembler performance. BMC Genomics 2011, 12:317.

42. Dohm JC, Lottaz C, Borodina T, Himmelbauer H: Substantial biases in ultra-short read data sets from high-throughput DNA sequencing. Nucleic Acids Res 2008, 36:e105.

43. Gibbs HL, Sanz L, Calvete JJ: Snake population venomics: proteomics-based analyses of individual variation reveals significant gene regulation effects on venom protein expression in Sistrurus rattlesnakes. J Mol Evol 2009, 68:113-125.

44. Fox JW, Serrano SMT: Structural considerations of the snake venom metalloproteinases, key members of the $\mathrm{M} 12$ reprolysin family of metalloproteinases. Toxicon 2005, 45:969-985.

45. Fox JW, Serrano SMT: Snake venom metalloproteinases. In Handbook of Venoms and Toxins of Reptiles. Edited by Mackessy SP. Boca Raton, Florida: CRC Press; 2010:95-113.

46. Mackessy SP: Venom composition in rattlesnakes: trends and biological significance. In The Biology of Rattlesnakes. Edited by Hayes WK, Beaman KR, Cardwell MD, Bush SP. Loma Linda, California: Loma Linda University Press; 2008:495-510

47. Du XY, Clemetson KJ: Reptile C-type lectins. In Handbook of Venoms and Toxins of Reptiles. Edited by Mackessy SP. Boca Raton, Florida: CRC Press; 2010:359-375

48. Walker JR, Nagar B, Young NM, Hirama T, Rini JM: X-ray crystal structure of a galactose-specific C-type lectin possessing a novel decameric quaternary structure. Biochemistry 2004, 43:3783-3792.

49. Serrano SMT, Maroun RC: Snake venom serine proteinases: sequence homology vs. substrate specificity, a paradox to be solved. Toxicon 2005, 45:1115-1132.

50. Phillips DJ, Swenson SD, Francis S, Markland J: Thrombin-like snake venom serine proteinases. In Handbook of Venoms and Toxins of Reptiles. Edited by Mackessy SP. Boca Raton, Florida: CRC Press; 2010: 139-154.

51. Lynch VJ: Inventing an arsenal: adaptive evolution and neofunctionalization of snake venom phospholipase $\mathbf{A}_{2}$ genes. $B M C$ Evol Biol 2007, 7:2 
52. Doley $R$, Zhou $X$, Kini RM: Snake venom phospholipase $\mathbf{A}_{\mathbf{2}}$ enzymes. In Handbook of Venoms and Toxins of Reptiles. Edited by Mackessy SP. Boca Raton, Florida: CRC Press; 2010:173-205.

53. Rádis-Baptista G, Oguiura N, Hayashi MAF, Camargo ME, Grego KF, Oliveira EB, Yamane T: Nucleotide sequence of crotamine isoform precursors from a single South American rattlesnake (Crotalus durissus terrificus). Toxicon 1999, 37:973-984.

54. Oguiura N, Boni-Mitake M, Rádis-Baptista G: New view on crotamine, a small basic polypeptide myotoxin from South American rattlesnake venom. Toxicon 2005, 46:363-370.

55. Straight RC, Glenn JL, Wolt TB, Wolfe MC: Regional differences in content of small basic peptide toxins in the venoms of Crotalus adamanteus and Crotalus horridus. Comp Biochem Physiol B 1991, 100:51-58.

56. Tan NH, Fung SY: Snake venom L-amino acid oxidases. In Handbook of Venoms and Toxins of Reptiles. Edited by Mackessy SP. Boca Raton, Florida: CRC Press; 2010:221-235.

57. Heyborne WH, Mackessy SP: Cysteine-rich secretory proteins in reptile venoms. In Handbook of Venoms and Toxins of Reptiles. Edited by Mackessy SP. Boca Raton, Florida: CRC Press; 2010:325-336.

58. Yamazaki Y, Hyodo F, Morita T: Wide distribution of cysteine-rich secretory proteins in snake venoms: isolation and cloning of novel snake venom cysteine-rich secretory proteins. Arch Biochem Biophys 2003, 412:133-141.

59. Yamazaki Y, Morita T: Structure and function of snake venom cysteine-rich secretory proteins. Toxicon 2004, 44:227-231.

60. Pung YF, Wong PTH, Kumar PP, Hodgson WC, Kini RM: Ohanin, a novel protein from king cobra venom, induces hypolocomotion and hyperalgesia in mice. J Bio/ Chem 2005, 280: 13137-13147.

61. Pung YF, Kumar SV, Rajagopalan N, Fry BG, Kumar PP, Kini RM: Ohanin, a novel protein from king cobra venom: its CDNA and genomic organization. Gene 2006, 371:246-256.

62. Junqueira-de-Azevedo ILM, Ching ATC, Carvalho E, Faria F, Nishiyama Jr MY, Ho PL, Diniz MRV: Lachesis muta (Viperidae) cDNAs reveal diverging pit viper molecules and scaffolds typical of cobra (Elapidae) venoms: implications for snake toxin repertoire evolution. Genetics 2006, 173:877-889.

63. Aird SD: Ophidian envenomation strategies and the role of purines. Toxicon 2002, 40:335-393.

64. Aird SD: The role of purine and pyrimidine nucleosides in snake venoms. In Handbook of Venoms and Toxins of Reptiles. Edited by Mackessy SP. Boca Raton, Florida: CRC Press; 2010:393-419.

65. Dhananjaya BL, Vishwanath BS, D'Souza CJM: Snake venom nucleases, nucleotidases, and phosphomonoesterases. In Handbook of Venoms and Toxins of Reptiles. Edited by Mackessy SP. Boca Raton, Florida: CRC Press; 2010:155-171.

66. Shafqat J, Zaidi ZH, Jörnvall H: Purification and characterization of a chymotrypsin Kunitz inhibitor type of polypeptide from the venom of cobra (Naja naja naja). FEBS Lett 1990, 275:6-8.

67. Harrison RA, Ibison F, Wilbraham D, Wagstaff SC: Identification of cDNAs encoding viper venom hyaluronidases: cross-generic sequence conservation of full-length and unusually short variant transcripts. Gene 2007, 392:22-33

68. Kemparaju K, Girish KS, Nagaraju S: Hyaluronidases, a neglected class of glycosidases from snake venom: beyond a spreading factor. In Handbook of Venoms and Toxins of Reptiles. Edited by Mackessy SP. Boca Raton, Florida: CRC Press; 2010:237-258.

69. Pawlak J, Kini RM: Snake venom glutaminyl cyclase. Toxicon 2006, 48:278-286

70. Fry BG, Scheib H, van der Weerd L, Young B, McNaughtan J, Ramjan SFR, Vidal N, Poelmann RE, Norman JA: Evolution of an arsenal. Mol Cell Proteomics 2008, 7:215-246.

71. Rehana S, Kini RM: Molecular isoforms of cobra venom factor-like proteins in the venom of Austrelaps superbus. Toxicon 2007, 50:32-52.

72. Eggertsen G, Lind P, Sjöquist J: Molecular characterization of the complement activating protein in the venom of the Indian cobra (Naja n. siamensis). Mol Immunol 1981, 18:125-133.

73. Conesa A, Götz S, García-Gómez JM, Terol J, Talón M, Robles M: Blast2GO: a universal tool for annotation, visualization and analysis in functional genomics research. Bioinformatics 2005, 21:3674-3676.
74. McCue MD: Cost of producing venom in three North American pitviper species. Copeia 2006, 2006:818-825.

75. Mackessy SP, Baxter LM: Bioweapons synthesis and storage: the venom gland of front-fanged snakes. Zool Anz 2006, 245:147-159.

76. Wang Q, Zhang Z, Blackwell K, Carmichael GG: Vigilins bind to promiscuously A-to-I-edited RNAs and are involved in the formation of heterochromatin. Curr Biol 2005, 15:384-391.

77. Nishikura K: Functions and regulation of RNA editing by ADAR deaminases. Annu Rev Biochem 2010, 79:321-349.

78. Hartl FU: Molecular chaperones in cellular protein folding. Nature 1996, 381:571-580.

79. Fink AL: Chaperone-mediated protein folding. Physiol Rev 1999, 79:425-449.

80. Young JC, Agashe VR, Siegers K, Hartl FU: Pathways of chaperone-mediated protein folding in the cytosol. Nat Rev Mol Cell Biol 2004, 5:781-791

81. Finley D: Recognition and processing of ubiquitin-protein conjugates by the proteasome. Annu Rev Biochem 2009 78:477-513.

82. Buchberger A, Bukau B, Sommer T: Protein quality control in the cytosol and the endoplasmic reticulum: brothers in arms. $\mathrm{Mo} / \mathrm{Cell}$ 2010, 40:238-252.

83. Bagola K, Mehnert M, Jarosch E, Sommer T: Protein dislocation from the ER. Biochim Biophys Acta 2011, 1808:925-936.

84. Huang KF, Chiou SH, KO TP, Wang AHJ: Determinants of the inhibition of a Taiwan habu venom metalloproteinase by its endogenous inhibitors by X-ray crystallography and synthetic inhibitor analogues. Eur J Biochem 2002, 269:3047-3056.

85. Richards R, St Pierre L, Trabi M, Johnson LA, de Jersey J, Masci PP, Lavin $\mathrm{MF}$ : Cloning and characterization of novel cystatins from elapid snake venom glands. Biochimie 2011, 93:659-668.

86. McCleary RJR, Heard DJ: Venom extraction from anesthetized Florida cottonmouths, Agkistrodon piscivorus conanti, using a portable nerve stimulator. Toxicon 2010, 55:250-255.

87. Rotenberg D, Bamberger ES, Kochva E: Studies on ribonucleic acid synthesis in the venom glands of Vipera palaestinae (Ophidia Reptilia). Biochem J 1971, 121:609-612.

88. Mortazavi A, Williams BA, McCue K, Schaeffer L, Wold B: Mapping and quantifying mammalian transcriptomes by RNA-Seq. Nat Methods 2008, 5:621-628.

89. Bentley DR, Balasubramanian S, Swerdlow HP, Smith GP, Milton J, Brown CG, Hall KP, Evers DJ, Barnes CL, Bignell HR, Boutell JM, Bryant J, Carter RJ, Cheetham RK, Cox AJ, Ellis DJ, Flatbush MR, Gormley NA, Humphray SJ, Irving LJ, Karbelashvili MS, Kirk SM, Li H, Liu X, Maisinger KS, Murray LJ, Obradovic B, Ost T, Parkinson ML, Pratt MR, Rasolonjatovo IMJ, Reed MT, Rigatti R, Rodighiero C, Ross MT, Sabot A, Sankar SV, Scally A, Schroth GP, Smith ME, Smith VP, Spiridou A, Torrance PE, Tzonev SS, Vermaas EH, Walter K, Wu X, Zhang L, Alam MD, Anastasi C, Aniebo IC, Bailey DMD, Bancarz IR, Banerjee S, Barbour SG, Baybayan PA, Benoit VA, Benson KF, Bevis C, Black PJ, Boodhun A, Brennan JS, Bridgham JA, Brown RC, Brown AA, Buermann DH, Bundu AA, Burrows JC, Carter NP, Castillo N, Chiara E, Catenazzi M, Chang S, Neil Cooley R, Crake NR, Dada OO, Diakoumakos KD, Dominguez-Fernandez B, Earnshaw DJ, Egbujor UC, Elmore DW Etchin SS, Ewan MR, Fedurco M, Fraser LJ, Fuentes Fajardo KV, Furey WS, George D, Gietzen KJ, Goddard CP, Golda GS, Granieri PA, Green DE, Gustafson DL, Hansen NF, Harnish K, Haudenschild CD, Heyer NI, Hims MM, Ho JT, Horgan AM, Hoschler K, Hurwitz S, Ivanov DV, Johnson MQ James T, Jones TAH, Kang GD, Kerelska TH, Kersey AD, Khrebtukova I, Kindwall AP, Kingsbury Z, Kokko-Gonzales PI, Kumar A, Laurent MA, Lawley CT, Lee SE, Lee X, Liao AK, Loch JA, Lok M, Luo S, Mammen RM, Martin JW, McCauley PG, McNitt P, Mehta P, Moon KW, Mullens JW, Newington T, Ning Z, Ng BL, Novo SM, O’Neill MJ, Osborne MA, Osnowski A, Ostadan O, Paraschos LL, Pickering L, Pike AC, Pike AC, Pinkard DC, Pliskin DP, Podhasky J, Quijano VJ, Raczy C, Rae VH, Rawlings SR, Rodriguez AC, Roe PM, Rogers J, Bacigalupo MCR, Romanov N, Romieu A, Roth RK, Rourke NJ, Ruediger ST, Rusman E, Sanches-Kuiper RM, Schenker MR, Seoane JM, Shaw RJ, Shiver MK, Short SW, Sizto NL, Sluis JP, Smith MA, Sohna JES, Spence EJ, Stevens K, Sutton N, Szajkowski L, Tregidgo CL, Turcatti G, vandeVondele S, Verhovsky Y, Virk SM, Wakelin S, Walcott GC, Wang J, Worsley GJ, Yan J, Yau L, Zuerlein M, Rogers J, Mullikin JC, Hurles ME, McCooke NJ, West JS, Oaks FL, Lundberg PL, Klenerman D, Durbin R, 
Smith AJ: Accurate whole human genome sequencing using reversible terminator chemistry. Nature 2008, 456:53-59.

90. Robertson G, Schein J, Chiu R, Corbett R, Field M, Jackman SD, Mungall K, Lee S, Okada HM, Qian JQ, Griffith M, Raymond A, Thiessen N, Cezard T, Butterfield YS, Newsome R, Chan SK, She R, Varhol R, Kamoh B, Prabhu AL, Tam A, Zhao Y, Moore RA, Hirst M, Marra MA, Jones SJM, Hoodless PA,

Birol I: De novo assembly and analysis of RNA-seq data. Nat Methods 2010, 7:909-912.

doi:10.1186/1471-2164-13-312

Cite this article as: Rokyta et al:: The venom-gland transcriptome of the eastern diamondback rattlesnake (Crotalus adamanteus). BMC Genomics 2012 13:312.

\section{Submit your next manuscript to BioMed Central} and take full advantage of:

- Convenient online submission

- Thorough peer review

- No space constraints or color figure charges

- Immediate publication on acceptance

- Inclusion in PubMed, CAS, Scopus and Google Scholar

- Research which is freely available for redistribution 